\title{
The dynamic response of prone-to-fall columns to ambient vibrations: comparison between measurements and numerical modelling
}

\author{
J. Valentin, ${ }^{1,2}$ A. Capron, ${ }^{1,2}$ D. Jongmans, ${ }^{1,2}$ L. Baillet, ${ }^{1,2}$ P. Bottelin, ${ }^{3}$ F. Donze, ${ }^{4}$ \\ E. Larose ${ }^{1,2}$ and A. Mangeney ${ }^{5,6}$ \\ ${ }^{1}$ Univ. Grenoble Alpes, ISTerre, F-38041 Grenoble, France.E-mail: denis.jongmans@univ-grenoble-alpes.fr \\ ${ }^{2}$ CNRS, ISTerre, F-38041 Grenoble, France \\ ${ }^{3}$ Géosciences Environnement Toulouse (GET), Observatoire Midi-Pyrénées, Université de Toulouse, CNRS, IRD, 14 avenue Edouard Belin, \\ F-31400 Toulouse, France \\ ${ }^{4}$ 3SR, Univ. Grenoble Alpes, CNRS, F-38000 Grenoble, France \\ ${ }^{5}$ Institut de Physique du Globe de Paris, Sorbonne Paris Cité, Univ. Paris Diderot, UMR 7154 CNRS, F-75005 Paris, France \\ ${ }^{6}$ ANGE team, CEREMA, Inria, Lab. J.-L. Lions, CNRS, F-75589 Paris, France
}

Accepted 2016 November 22. Received 2016 November 21; in original form 2016 May 2

\begin{abstract}
S UMMAR Y
Seismic noise measurements (ambient vibrations) have been increasingly used in rock slope stability assessment for both investigation and monitoring purposes. Recent studies made on gravitational hazard revealed significant spectral amplification at given frequencies and polarization of the wave-field in the direction of maximum rock slope displacement. Different properties (resonance frequencies, polarization and spectral ratio amplitudes) can be derived from the spectral analysis of the seismic noise to characterize unstable rock masses. The objective here is to identify the dynamic parameters that could be used to gain information on prone-to-fall rock columns' geometry. To do so, the dynamic response of prone-to-fall columns to seismic noise has been studied on two different sites exhibiting cliff-like geometry. Dynamic parameters (main resonance frequency and spectral ratio amplitudes) that could characterize the column decoupling were extracted from seismic noise and their variations were studied taking into account the external environmental parameter fluctuations. Based on this analysis, a two-dimensional numerical model has been set up to assess the influence of the rear vertical fractures identified on both sites on the rock column motion response. Although a simple relation was found between spectral ratio amplitudes and the rock column slenderness, it turned out that the resonance frequency is more stable than the spectral ratio amplitudes to characterize this column decoupling, provided that the elastic properties of the column can be estimated. The study also revealed the effect of additional remote fractures on the dynamic parameters, which in turn could be used for detecting the presence of such discontinuities.
\end{abstract}

Key words: Numerical modelling.

\section{INTRODUCTION}

During the last two decades, seismic noise measurements have been increasingly used in gravitational (natural) hazard assessment for both investigation and monitoring purposes. The seismic noise denotes ambient vibrations of the ground caused by natural sources (ocean waves striking the coast, wind effects, river flows), as well as by human activity (industrial machinery, train and car traffic) and cover a broad frequency range from less than $10 \mathrm{mHz}$ to one hundred $\mathrm{Hz}$ (Bonnefoy-Claudet et al. 2006). In the low-frequency domain, the seismic noise is dominated by natural sources, while at high frequency the noise is produced by human activity. This wide frequency range allows ambient vibrations to be used for investigating geological or civil engineering structures in a wide variety of sizes, from the lithospheric or crust scale (Campillo 2006) to a few m-thick landslides and rock structures (Danneels et al. 2008; Levy et al. 2010; Mainsant et al. 2012; Starr et al. 2015) or buildings (Clinton et al. 2006; Michel et al. 2008).

On unstable slopes, ambient vibrations have been applied in very different ways for reconnaissance, depending on the investigation purpose and the landslide type. The simplest way to extract information on a given site from ambient vibrations is to perform single-station measurements with a three-component sensor and to process the records using the so-called Nakamura's method 
(Nakamura 1989). It consists in computing the spectral ratio between the horizontal and vertical components $(H / V)$ of ambient noise. The $H / V$ ratio has been experimentally and numerically proved to provide the fundamental resonance frequency of the site (e.g. Bonnefoy-Claudet et al. 2006; Haghshenas et al. 2008; Albarello \& Lunedei 2010). For a single infinite horizontal homogeneous soft layer overlying bedrock, this fundamental frequency is given by $f_{0}=V s / 4 h$ where $V s$ is the soft layer shear wave velocity and $h$ is the layer thickness. Knowing an estimate of $V s$ allows the thickness of the soft layer to be calculated.

In the case of landslides exhibiting a clear contrast in seismic velocity over the slip surface, the method is able to locally determine the landslide thickness, provided that the landslide's lateral extension is much greater than the vertical one (Jongmans \& Garambois 2007). This method was successfully applied on clayey landslides affecting gentle slopes (e.g. Gallipoli et al. 2000; Méric et al. 2007; Danneels et al. 2008). However, in the thick lacustrine deposits of the Avignonet landslide (French Alps), Jongmans et al. (2009) showed that the $H / V$ peak frequencies were not linked to the slip surface depth but rather to the deeper clay-bedrock interface, where the main contrast in seismic velocity occurs. In more complex geometry (2-D/3-D structure), the $H / V$ ratios might show an azimuthal variation, resulting from a resonance anisotropy. This phenomenon was reported by some authors (Méric et al. 2007; Del Gaudio et al. 2008) on low to middle slopes. At the Caramanico Terme site in the Apennine chain (central Italy), Del Gaudio et al. $(2008,2014)$ showed that the site exhibits directional spectral amplification and that the $H / V$ spectral ratios are approximately oriented as the site response (standard spectral ratios). Analysis of ambient vibrations and of small regional earthquakes records was also performed at the top of the Randa rock cliff site (Burjánek et al. 2010; Moore et al. 2011), which experienced two catastrophic failures in April and May 1991. The recorded wavefield revealed significant spectral amplification and polarization in the direction of maximum slope displacement within the unstable rock mass, which the authors relate to the presence of near-vertical deep fractures (Moore et al. 2011). Small-aperture seismic arrays were deployed at a potentially unstable slope in the same area (Burjánek et al. 2012). Array technique analysis showed that the wavefield was dominated by standing waves characterized by directional horizontal spectral amplification oriented perpendicular to open tension cracks. For an unstable rock column, Levy et al. (2010) derived its main resonance frequency $f_{0}$ from seismic noise records and observed a drop in $f_{0}$ prior to column collapse. Thereafter, Bottelin et al. (2013a) studied the dynamic response of four prone-to-fall rock compartments showing diverse morphology, failure mechanism, geological context and volumes. Every single cliff site exhibited well-defined polarized spectral peaks at distinct frequencies. The predominant spectral peak was systematically measured at the lowest resonance frequency $f_{0}$ with a polarization perpendicular to the rear fracture.

This review shows that different characteristics of the seismic noise (peak frequencies interpreted as resonance frequencies, polarization, and the spectral ratios $H / V$ and $H / H$ ) could be derived from the spectral analysis of the recorded motion. For cliff-like sites, this paper aims to identify the key parameters that could be extracted from ambient vibrations and used to gain information on the prone-to-fall column geometry. We first analyse the dynamic response of prone-to-fall columns to seismic noise at two rocky sites, extracting several parameters (main resonance frequency, spectral ratio amplitudes) that could characterize the column decoupling, and studying their variations depending on external environmental factors. We then conduct a 2-D numerical modelling to understand the experimental data and to assess the influence of the rear fracture geometry on the motion characteristics. A simple relation has been found between spectral ratio amplitudes and the column slenderness (ratio of the column height and thickness). However, the resonance frequency appears to be less sensitive to climatic fluctuations to assess the column decoupling, whereas spectral ratio amplitudes provided a way to detect the presence of additional fractures. These results demonstrate the interest of combining these three parameters (resonance frequency and the two spectral ratio amplitudes).

\section{DATA PROCESSING RESULTS}

\subsection{Site characteristics}

Two cliff-like sites with exposed rock columns and with an easy top plateau access were instrumented. The first one (Les Arches) is located in the Western Alps (France), at the Southern end of the carbonate Vercors massif, $100 \mathrm{~km}$ South of Grenoble city (Fig. 1a). The cliff, which culminates at an elevation of about $1900 \mathrm{~m}$, is made of sub-horizontal meter-thick limestone layers (Levy et al. 2010). An unstable column about $30 \mathrm{~m}$ high, $15 \mathrm{~m}$ wide and $4.5 \mathrm{~m}$ thick (Figs 1b-d), for a volume of about $1000 \mathrm{~m}^{3}$ has been identified there. The rear fracture is about $1 \mathrm{~m}$ wide at the surface and is visible to $15 \mathrm{~m}$ depth. Seismic prospecting was carried out nearby and the limestone was found to be strongly fractured with $P$-wave and $S$-wave velocities of 2800 and $960 \mathrm{~m} \mathrm{~s}^{-1}$, respectively (Levy et al. 2010).

The second site (Bory) is located on the Piton de La Fournaise volcano (La Réunion Island, Indian Ocean) (Fig. 2a). The studied column was formed after the Dolomieu crater collapsed in April 2007 (Peltier et al. 2012). This event cut the already present but smaller Bory crater (semi-elliptic shape) and created new cliffs up to $300 \mathrm{~m}$ high along the crater walls (Fig. 2b). Numerous open hectometre-size fractures, parallel to the cliff, were observed in the Bory crater (Figs 2b and c). The $10000 \mathrm{~m}^{3}$ column is separated from the crater by an open fracture (about $1.5 \mathrm{~m}$ wide at the surface and deeper than $10 \mathrm{~m}$; Figs $2 \mathrm{~d}$ and e). The adjacent rock cliff is made of three layers, with from top to bottom: an $11 \mathrm{~m}$ thick dark basaltic layer, a $4 \mathrm{~m}$ reddish scoria layer and a thick basaltic layer (Fig. 2e). Seismic prospecting was performed at several sites on the remaining Bory crater (Bottelin 2014). The upper basalt layer was found to be strongly and heterogeneously fractured, with $P$ - and $S$-wave velocity varying from 630 to $1500 \mathrm{~m} \mathrm{~s}^{-1}$, and from 420 to $650 \mathrm{~m} \mathrm{~s}^{-1}$, respectively. These ranges of values for the near-surface velocity are also observed for other volcanoes (Perrier et al. 2012).

The two sites were equipped with short-period 3-C seismometers connected to Nanometrics Taurus stations. The seismometers were oriented northward and the seismic stations operated in continuous recording mode with a $250 \mathrm{~Hz}$ sampling frequency. Periods of study vary across the two sites. Les Arches is a semi-permanent observation site equipped with two seismometers (Fig. 1b). We considered the recording period between 2015 June 12 and 2015 July 28, and for which full 3-C data are available. Air temperature, rainfall and wind speed were recorded by the permanent meteorological station 'Jardins du Roi', located $3.2 \mathrm{~km}$ southwest from the site and $120 \mathrm{~m}$ below in altitude.

The Bory site (Fig. 2c) was temporary monitored in October 2012. Two seismometers ( $S 1$ and $S 2$ ) recorded continuously at the same location during three full days (2012 October 28 to 2012 November 1). A seismometer was also moved along a profile ( $S 3$ to $S 8$ ) and the ambient noise was recorded during $45 \mathrm{~min}$ at each 

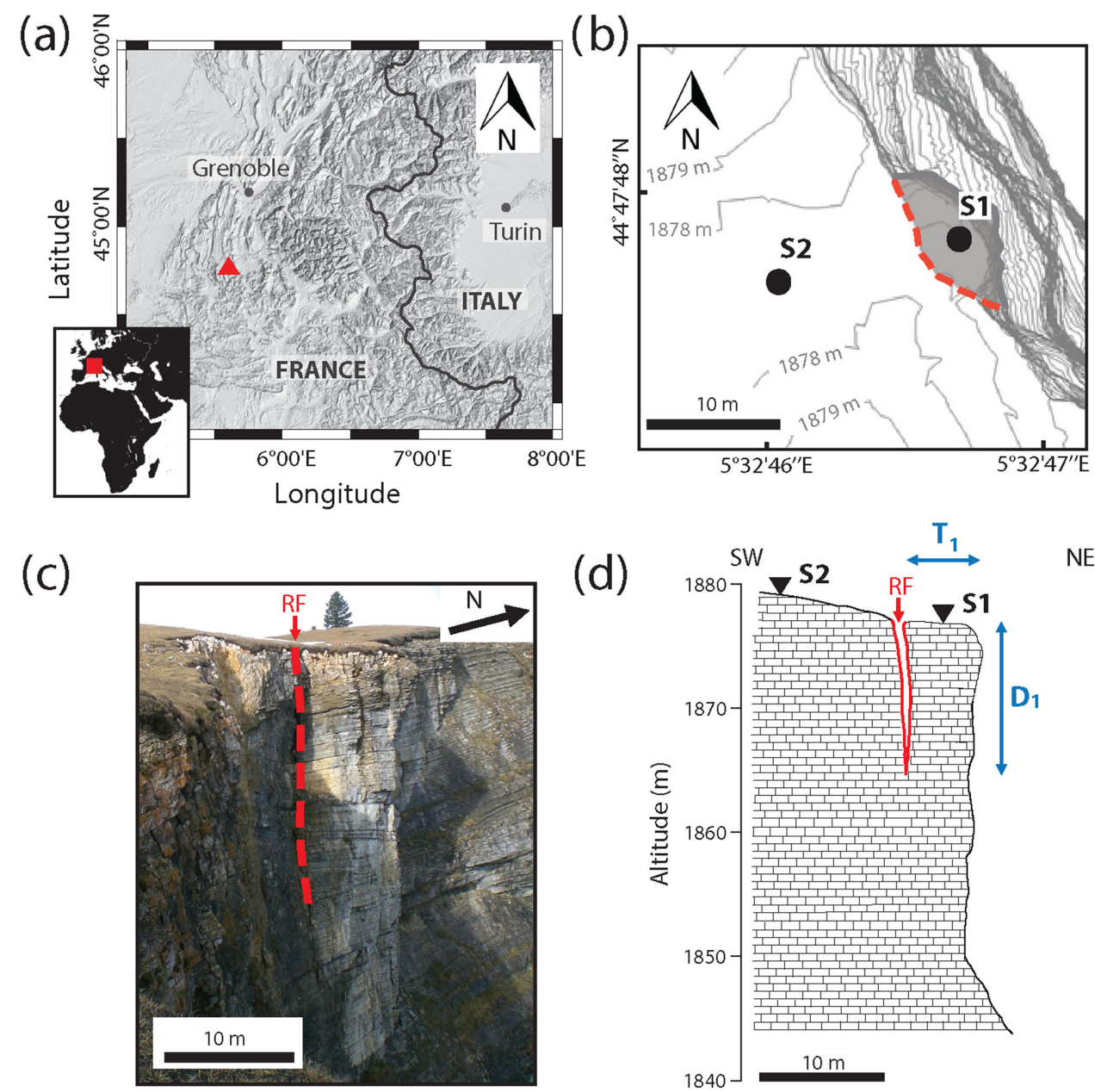

(d)

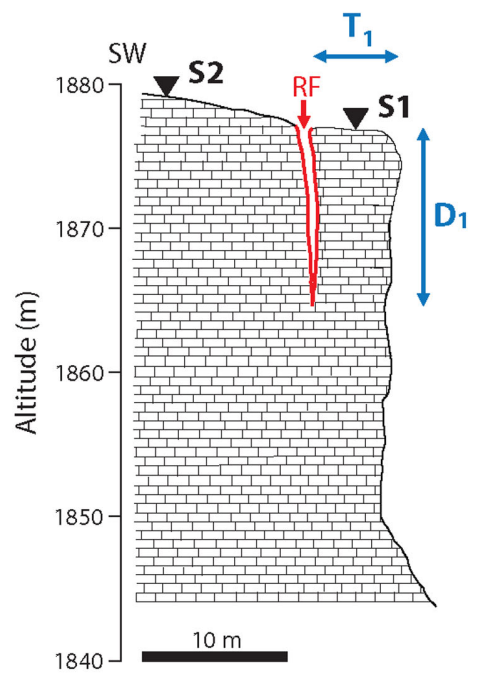

NE

For les Arches site, the polar plot of the normalized Fourier spectra (horizontal components) at sensor $S 1$ is displayed in Fig. 3(a). Fourier spectra were computed over a $24 \mathrm{hr}$ long period (2015 July 14) with $1^{\circ}$ azimuthal increment in the frequency range [0.5$10 \mathrm{~Hz}$. Azimuths are displayed clockwise with respect to the North, whereas the radial direction corresponds to the frequency axis. This plot exhibits a clear peak at an azimuth of $55^{\circ}$ with a frequency of $6 \mathrm{~Hz}$. It corresponds to a predominant motion oriented perpendicular to the rear fracture (Fig. 3b). This peak frequency was previously interpreted as the fundamental resonance frequency (first bending mode) of the column, using numerical modelling Bottelin et al. (2013b). The monitoring of the Fourier spectrum (horizontal motion $H$ oriented N55 $5^{\circ}$ during 1.5 months (from 2015 June 12 to 2015

July 28), along with the amplitudes of the $H / V$ and $H / H$ spectral ratios at $f_{0}\left(A_{H / V}\right.$ and $A_{H / H}$ amplitudes, respectively) and temperature and wind variations is shown in Fig. 3(b). The frequency $f_{0}$ exhibits variations ranging from 5.6 to $6.5 \mathrm{~Hz}$, and it clearly appears to be controlled by the temperature fluctuations. This in-phase relation is interpreted as resulting from the rear fracture closure induced by rock thermal expansion (Bottelin et al. 2013b). $A_{H / V}$ and $A_{H / H}$ values at the resonance frequency vary widely over time, from 2 to 30 and from 7 to more than 100, respectively (Fig. 3b). The $H / V$ and $H / H$ curves (mean and \pm one standard deviation, in log scale) for both sensors $S 1$ and $S 2$ are shown over the 1.5-month period in Figs 3(e) and (f). The mean $H / V$ value on the column ( $S 1)$ reaches about 15 at the average resonance frequency of $6.2 \mathrm{~Hz}$ with a high scattering (6 to 31 ). At the $S 2$ reference sensor, the mean $H / V$ curve remains almost flat and consistent, exhibiting values between 1 and 2 below $10 \mathrm{~Hz}$. The mean $A_{H / H}$ value is higher (33) than $A_{H / V}$, showing strong scattering (16 to 70). Higher $A_{H / V}$ and $A_{H / H}$ values are obtained during periods of strong wind (blue vertical bands, Fig. 3b). We computed the mean $A_{H / V}$ amplitude in successive $1 \mathrm{~m} \mathrm{~s}^{-1}$-wide wind speed classes (Fig. 3c). $A_{H / V}$ and $A_{H / H}$ values regularly increase with the wind speed, with a lower scattering for strong winds. This relation might result from the wind-induced seismic solicitation of the column in the vicinity of the sensor. This hypothesis was numerically tested with a $2-\mathrm{D}$ model by applying a horizontal wind 
(a)

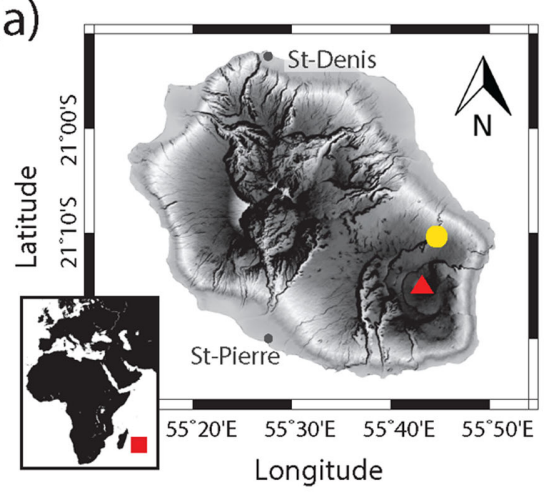

(c)

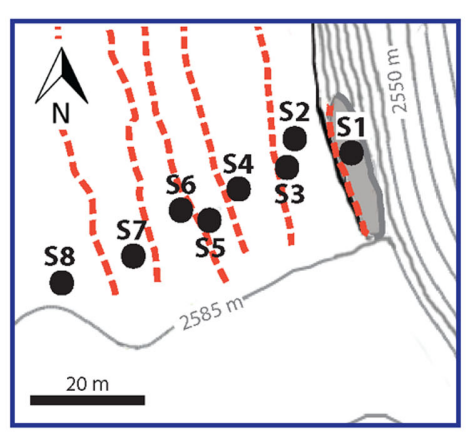

(d)

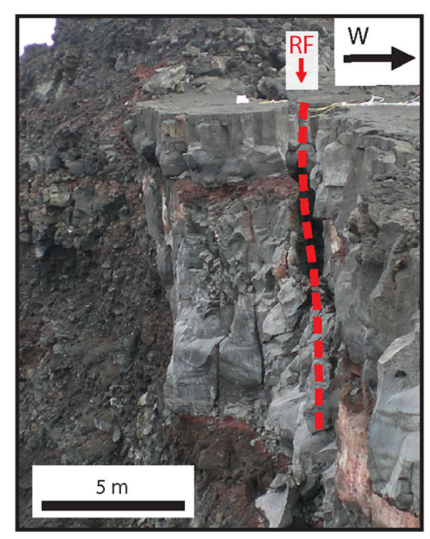

(b)

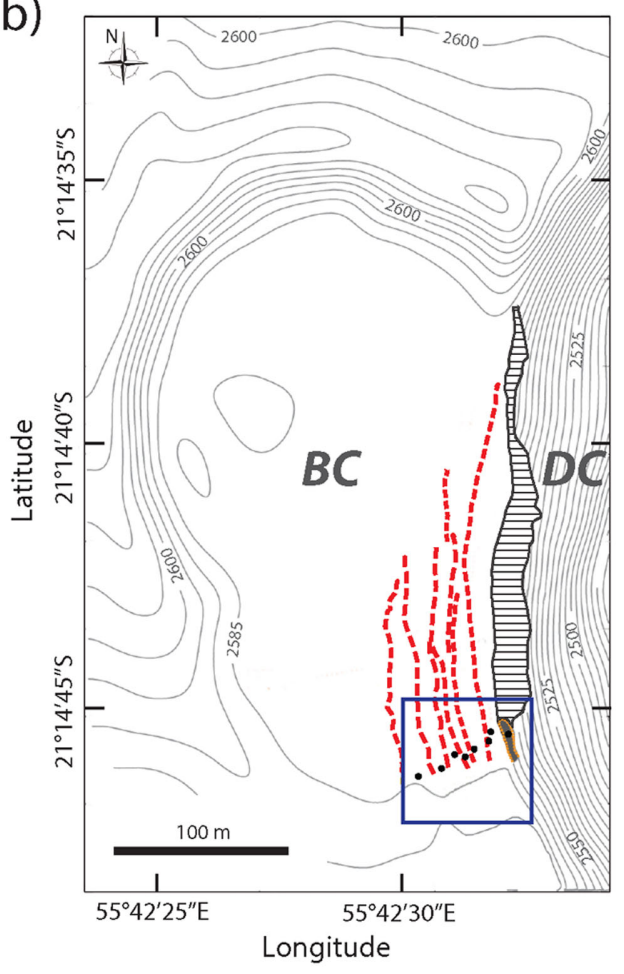

(e)

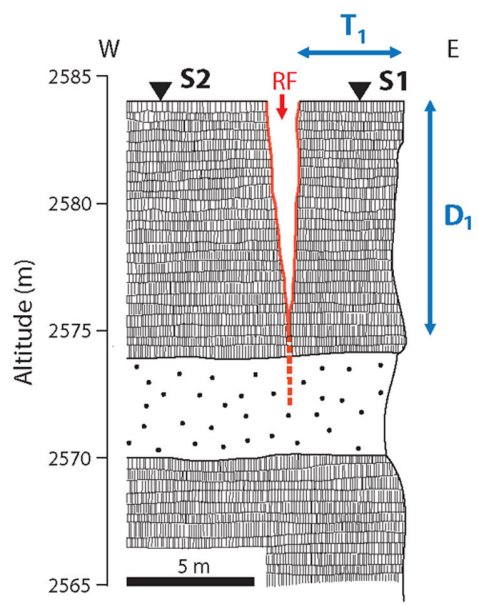

Figure 2. Bory Site (Piton de la Fournaise Volcano). (a) Map showing the location of the Bory crater (red triangle) and of the seismological reference station RER of the Geoscope network (yellow dot). (b) Contour map showing the older Bory crater (BC) truncated by the Dolomieu crater (DC). (c) Detailed contour map (rectangle in Fig. 2b) with the location of the sensors $S 1$ to $S 8$. (d) Picture of the prone-to-fall column, taken from the north. (e) Schematic geological section showing basaltic flows with an interbedded $4 \mathrm{~m}$ thick scoria layer (black dots). The rear fracture (RF) delineating the unstable column is shown with dashed red lines.

pressure $P_{w}$ on the cliff free surface. We used the simple equation $P_{w}=K \rho S_{w}{ }^{2}$ (Mendis et al. 2007), where $S_{w}$ is the wind speed, $K$ is a shape factor and $\rho$ is the air density, with strong winds $\left(S_{w}\right.$ between 3 and $5 \mathrm{~m} \mathrm{~s}^{-1}$ ). Results indicate that the wind speed increases the $H / V$ and $H / H$ ratios over a relatively wide frequency range (Appendix A; Fig. A1). At the peak frequency, the rise is about 20 per cent for $H / V$ and 80 per cent for $H / H, A_{H / V}$ and $A_{H / H}$ reaching values of 22 and 60 , however below the amplitudes of 30 and more than 100 (Fig. 3c) measured in strong wind conditions. These results suggest that the pressure of strong wind on the column could contribute to the observed ratio increase, without totally explaining its magnitude. Another factor could also originate from turbulence effects at the air/instrument/ground interface (Mucciarelli et al. 2005). Both sensors are superficially buried at Les Arches site, owing to rocky ground conditions. Enhanced horizontal component vibration could then be due to air flow rotation near the ground and/or turbulences in the fracture during windy periods.

In order to minimize the wind effect, the $H / V$ and $H / H$ curves were computed for wind speed weaker than $1 \mathrm{~m} \mathrm{~s}^{-1}$ (Figs $3 \mathrm{~h}$ and i, respectively). This condition yielded smaller values of mean $A_{H / V}$ and $A_{H / H}$ (10.8 and 30, respectively) with reduced scattering for $A_{H / H}$. However, these two parameters still exhibit greater variation than the resonance frequency $f_{0}$, suggesting that they are more sensitive to the environmental conditions. 
(a)

(c)
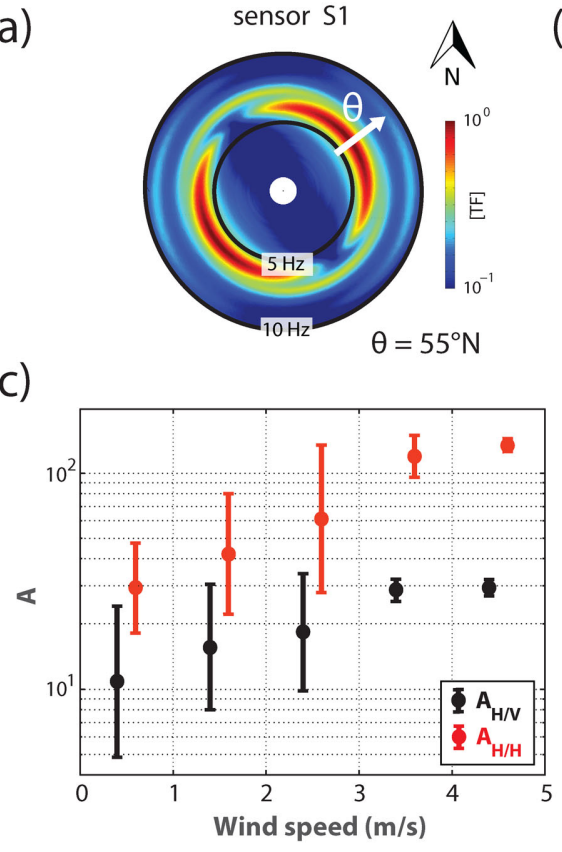

(d)

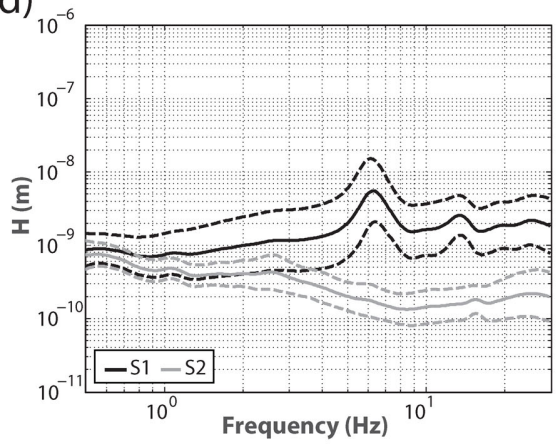

(g)

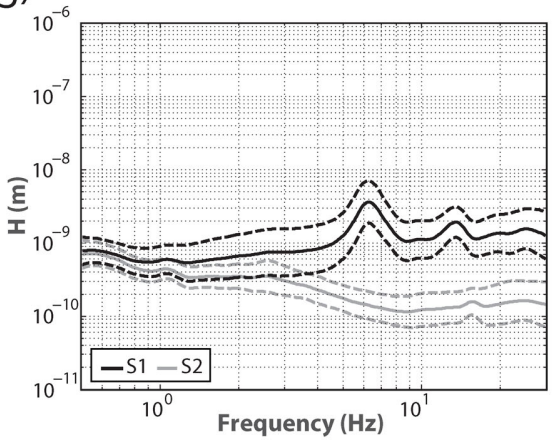

(b)
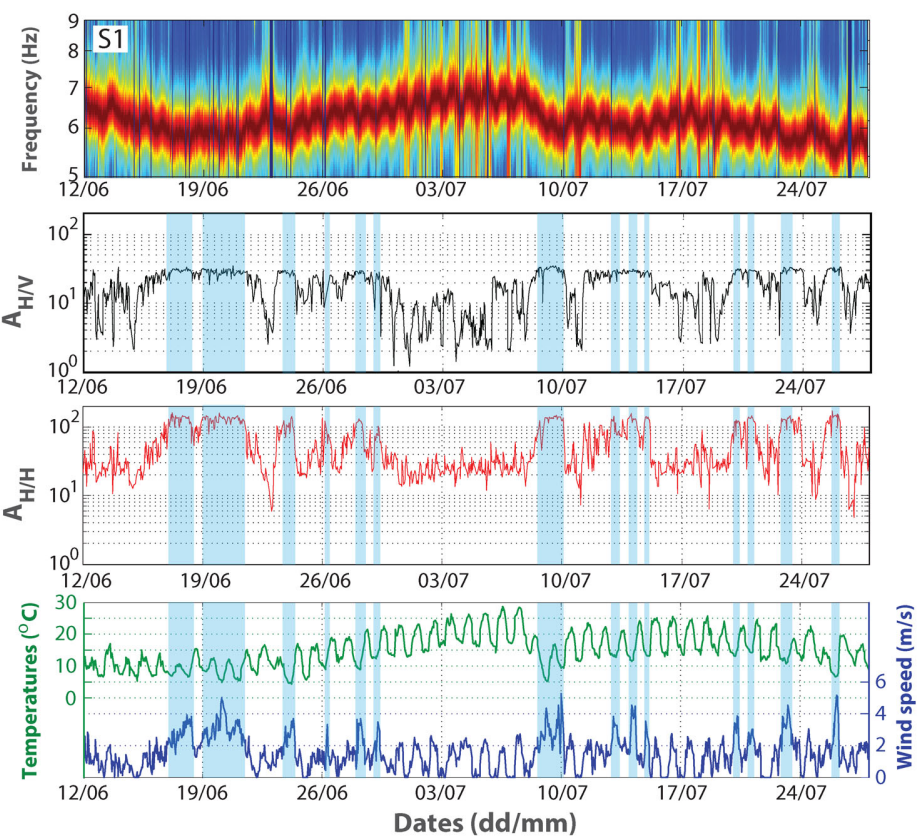

(e)

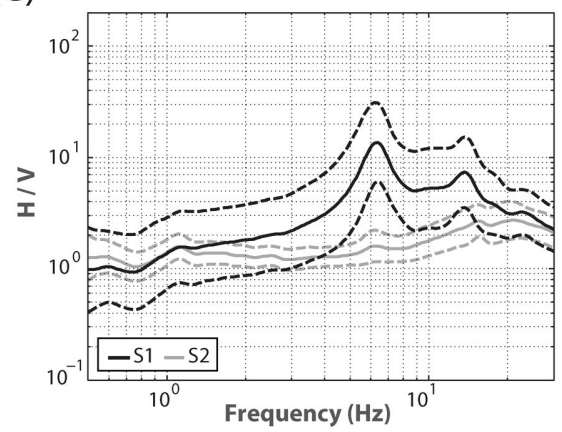

(f)

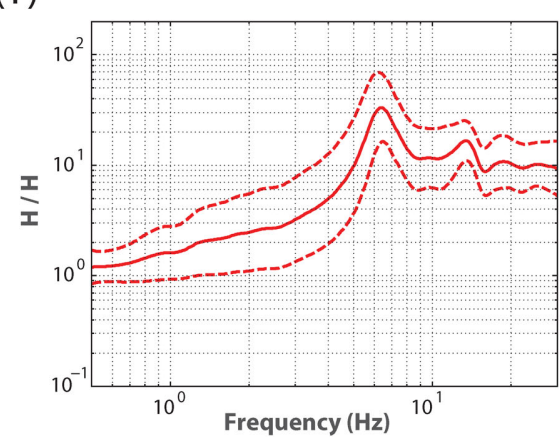

(i)

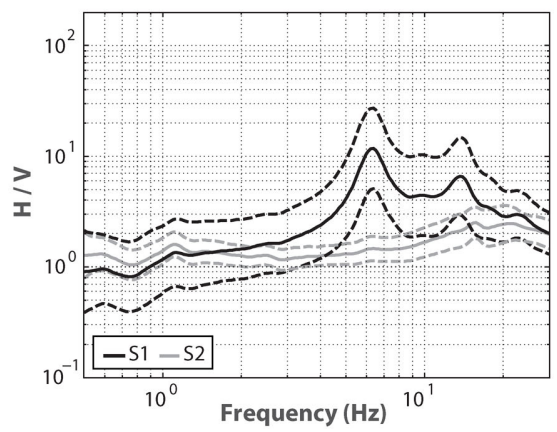

Figure 3. Les Arches site. (a) Polar plot of the normalized Fourier spectra at sensor $S 1$ (column), computed from a 1 hr long record (2015 July 14 ). The main peak is at $7 \mathrm{~Hz}\left(f_{0}\right.$ with a motion polarized in the $\mathrm{N} 55^{\circ}$ direction. (b) Top: Fourier spectra along the horizontal component $\mathrm{H}$ oriented perpendicular to the cliff $\left(\mathrm{N} 55^{\circ}\right)$ during 1.5 months (2015 June 12 to 2015 July 28). Middle: amplitudes of the $H / V$ and $H / H$ ratios $\left(A_{H / V}\right.$ and $\left.A_{H / H}\right)$ at $f_{0}$ during the same period. Bottom: temperature and wind speed curves measured at the permanent meteorological station during the same period. (c) $A_{H / V}(\mathrm{black})$ and $A_{H / H}$ (red) values (mean with error bars) at the resonance frequency as a function of wind speed. (d) Horizontal spectral motion at sensors $S 1$ (black) and $S 2$ (grey). (e) $H / V$ spectral ratios at the two sensors $S 1$ (black) and $S 2$ (grey). (f) $H / H$ spectral ratios (motion at sensor $S 1$ over motion at sensor $S 2$ in the N55 direction). (g) Same legend as (d) for wind speed weaker than $1 \mathrm{~m} \mathrm{~s}^{-1}$. (h) Same legend as (e) for wind speed weaker than $1 \mathrm{~m} \mathrm{~s} \mathrm{~s}^{-1}$. For diagrams (d) to (i), solid lines are mean curves and dashed lines represent \pm one standard deviation around the mean. All the spectra were computed for the same period (2015 June 12 to 2015 July 28).

\subsubsection{Bory site}

At the Bory site, the Fourier spectra polar plot (horizontal components) at sensor $S 1$ shows a clear peak at a frequency of $2.9 \mathrm{~Hz}$ for an azimuth of $\mathrm{N}^{\circ} 5^{\circ}$ (Fig. 4a). This peak corresponds to a motion perpendicular to the rear fracture (Fig. 2d). Similarly to the Les Arches site, this frequency is interpreted as the fundamental resonance frequency $f_{0}$ (bending vibrational mode) of the column. The Fourier 
(a)

(c)
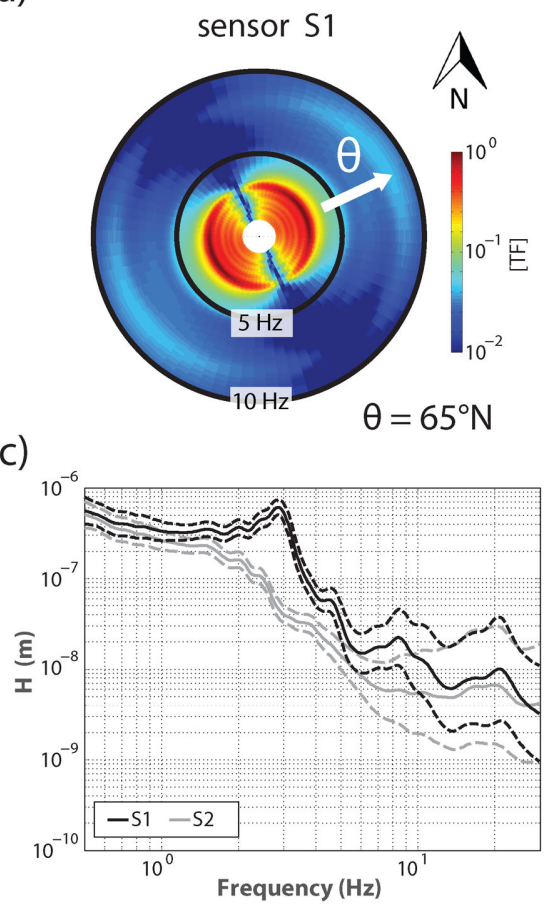

(f)

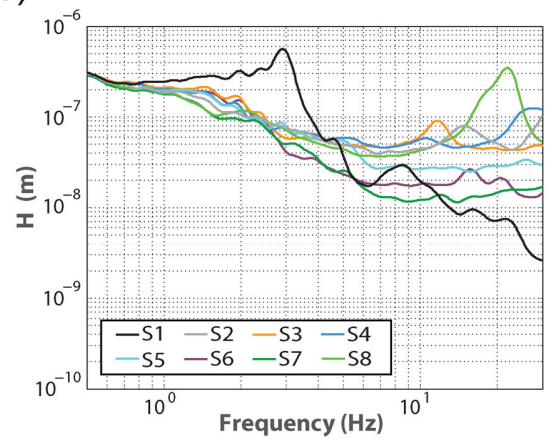

(b)
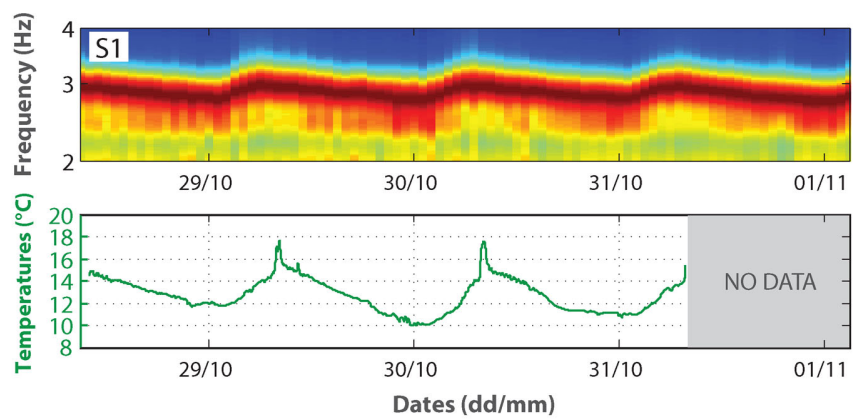

(d)

(e)

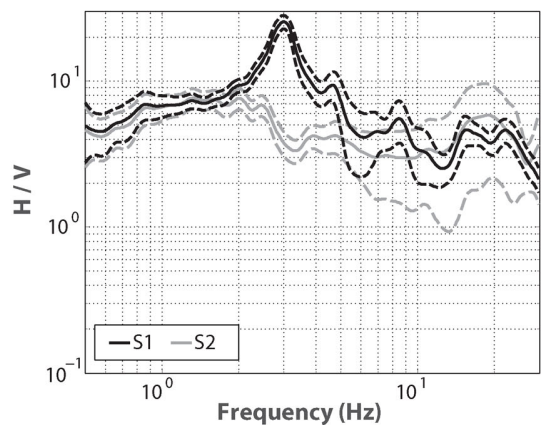

(g)

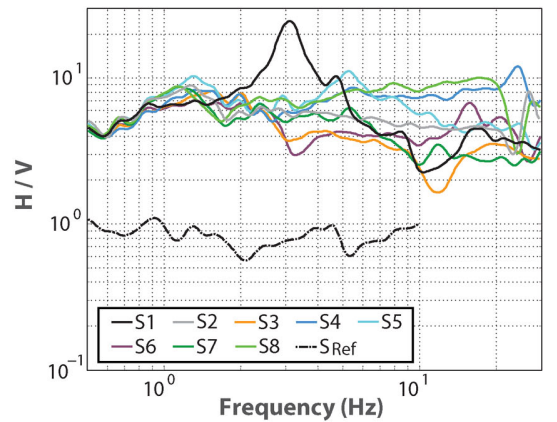

(h)
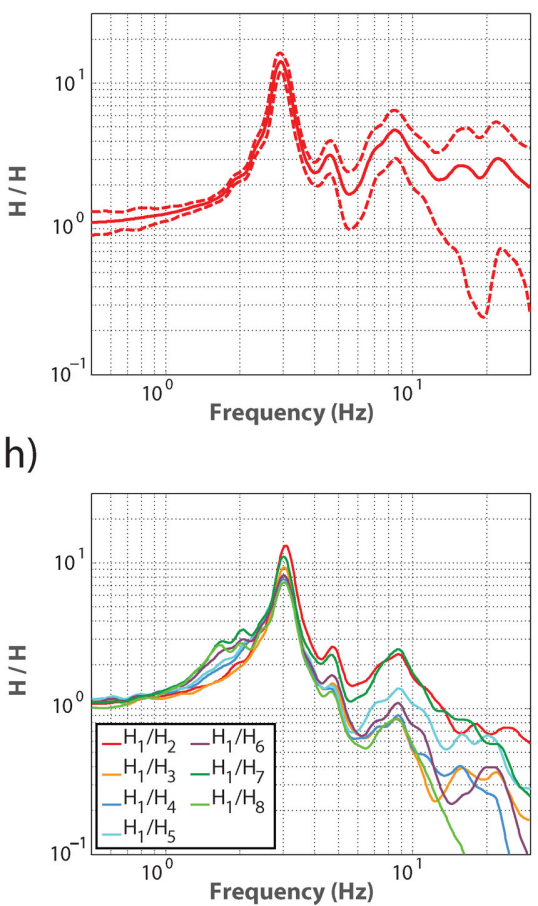

Figure 4. Bory site. (a) Polar plot of the normalized Fourier spectra at sensor $S 1$, computed from a $1 \mathrm{hr}$ long record (2012 October 29). The motion is polarized in the $\mathrm{N} 65^{\circ}$ direction. (b) Normalized seismic noise spectrum and air temperature as a function of time for the $3 \mathrm{~d}$ experiment. (c) Fourier spectra along the horizontal component oriented perpendicular to the cliff for the two sensors $S 1$ and $S 2$ (3 d duration). Solid lines are mean curves and dashed lines represent mean \pm one standard deviation. (d) $H / V$ spectral ratios (mean \pm one standard deviation) computed at the two sensors $S 1$ and $S 2$ ( $3 \mathrm{~d}$ duration). (e) $H / H$ spectral ratio (mean \pm one standard deviation) between the horizontal components (perpendicular to the cliff) at sensors $S 1$ and $S 2$ ( 3 d duration). (f) Mean horizontal spectrum (perpendicular to the cliff) for the 8 sensors $S 1$ to $S 8$ (45 min duration). (g) Mean $H / V$ spectral ratios computed at the 8 sensors $S 1$ to $S 8$ and at the permanent station $\operatorname{SRef}(45 \mathrm{~min}$ duration). (h) Mean $H / H$ Spectral ratios between the horizontal component (perpendicular to the cliff) at sensor $S 1$ and the same component at the 7 other sensors (45 min duration). Note the difference between panels (e) and (h) over $5 \mathrm{~Hz}$.

spectrum variation during the $3 \mathrm{~d}$ of experiment, along with the air temperature fluctuations is shown in Fig. 4(b). The two curves are globally in-phase, with a variation in $f_{0}$ of $\pm 0.2 \mathrm{~Hz}$ around the average under thermal variations of about $8^{\circ} \mathrm{C}\left(\right.$ from $10^{\circ} \mathrm{C}$ to $18^{\circ} \mathrm{C}$ between day and night). This observation is consistent with the results obtained at Les Arches site and reveals the thermal response of the decoupled column.

The $\mathrm{N} 65^{\circ}$ oriented Fourier spectra are shown for sensors $S 1$ and $S 2$ in Fig. 4(c). The spectrum on the column exhibits a peak at about $3 \mathrm{~Hz}$, not observable on the spectral motion on the rock mass. Both spectra show high amplitudes in the low frequency range (below $2 \mathrm{~Hz}$ ) and show significant scattering over $4 \mathrm{~Hz}$. The mean spectral curves for the 8 stations are shown in Fig. 4(f). The striking feature is that all sensors located in the Bory crater $(S 2$ to $S 8$ ) exhibit similar spectra in the low frequency range, with a scattering that increases with frequency over $4 \mathrm{~Hz}$. The $H / V$ curves were computed for the two sensors $S 1$ and $S 2$ ( 3 d recordings; mean \pm one standard deviation curves, Fig. 4d) and for sensors $S 1$ to $S 8$ (45 min recordings; mean curves, Fig. $4 \mathrm{~g}$ ). The $S 1$ curve shows a peak with a mean amplitude $A_{H / V}=25$ at a frequency of $3 \mathrm{~Hz}$, associated to a plateau-like shape (amplitude of about 7) in the low frequency band $0.8-2.5 \mathrm{~Hz}$. This feature is also observed for $S 2$ and $S 3$, while the plateau extends to higher frequencies for $S 4$ and $S 5$ (Fig. 4g). Interestingly, the $H / V$ curve computed at a permanent station located $8.5 \mathrm{~km}$ from the Bory crater on the Piton de la Fournaise Volcano does not show such large amplitudes (Fig. 4g), suggesting that the plateau in the $H / V$ curve results from a local effect. Finally, the $H_{1} / H_{n}$ spectral ratio curves (with $n$ corresponding to station $\left.S_{n}\right)$ are plotted in Figs 4(e) $(n=2)$ and (h) $(n=2$ to 8$)$. All curves exhibit a peak at the same frequency (around $3 \mathrm{~Hz}$ ) with 


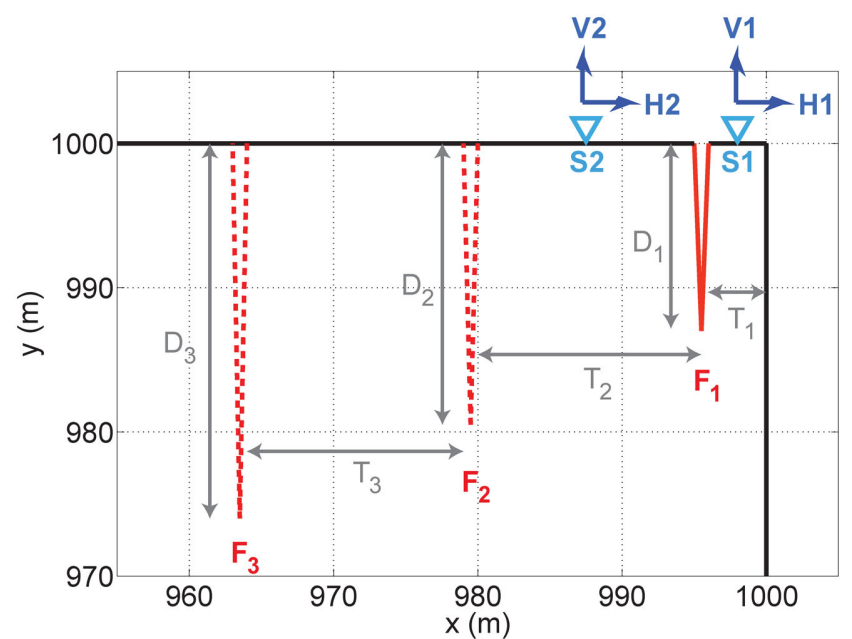

Figure 5. Geometry of the cliff with the presence of a rear fracture $\left(F_{1}\right.$ : red solid line) defining a prone-to-fall column $\left(T_{1}, D_{1}\right)$. The horizontal and vertical motions $(H$ and $V$ ) are computed at two sensors $S 1$ and $S 2$. The locations of two other rear fractures $\left(F_{2}\right.$ and $\left.F_{3}\right)$ are indicated with red dashed lines.

$A_{H / H}$ amplitudes varying from 8 to 13 according to the location of the reference station. The $H_{1} / H_{n}$ curves exhibit similar shapes from $0.5 \mathrm{~Hz}$ to $4 \mathrm{~Hz}$ and increased discrepancy at high frequency where the $H / H$ ratios drop. At low frequency, all $H_{1} / H_{n}$ ratios are close to 1 , indicating that all sensors are affected by the same local effect appearing on the $H / V$ curves. These results suggest that the seismic noise measured by the 8 sensors is affected by an amplification effect on the horizontal component, which is limited to the Bory crater. Another significant feature is the difference observed at high frequency between the $H_{1} / H_{n}$ curves of Figs 4(e) and (h), computed for two different recording times ( $3 \mathrm{~d}$ and $45 \mathrm{~min}$, respectively). This observation will be discussed further.

At the two sites, the processing of the seismic noise allowed the natural frequency $f_{0}$ of a prone-to-fall column to be easily retrieved from the horizontal motion spectrum or from the spectral ratios $H / V$ and $H / H$. Significant differences in the spectral ratios were however found between the two sites: (1) $A_{H / H}$ is higher than $A_{H / V}$ at les Arches site, while it is the contrary at the Bory site. (2) The shape of the $H / V$ curve is more complex at Bory, with a bump in the frequency range below $f_{0}$. In order to understand these differences and to test the capacity to derive the rear fracture depth from seismic noise measurements, 2-D numerical modelling has been applied.

\section{2-D NUMERICAL MODELLING}

\subsection{Numerical model and tests}

First, the 2-D response of a homogeneous cliff including a single fracture of depth $D_{1}$ and delineating a column of thickness $T_{1}$ (Fig. 5) is numerically studied. This geometry approximates the shape of the studied column at Les Arches site (Fig. 1d), with $T_{1}$ $=4 \mathrm{~m}$ and $D_{1}=15 \mathrm{~m}$. The dynamic characteristics of the medium (Table 1) are based on previous seismic prospecting results (Levy et al. 2010), considering a slightly less fractured medium. Modelling was performed using the Finite Element software Comsol (http://www.comsol.com) with triangular finite elements. The modelled medium (Fig. 6a) is a square of $1000 \mathrm{~m}$ side with two free boundaries (the cliff and the plateau) and two absorbing boundaries (shown in red in Fig. 6a). A mesh size $s_{m}$ of $4 \mathrm{~m}$ with a refined
Table 1. Medium dynamic characteristics chosen for numerical modelling (Les Arches site).

\begin{tabular}{lcc}
\hline Characteristic & Symbol & Value \\
\hline Young's modulus & $E$ & $10 \mathrm{GPa}$ \\
Poisson's ratio & $v$ & 0.35 \\
Density & $\rho$ & $2500 \mathrm{~kg} \mathrm{~m}^{-3}$ \\
$P$-wave velocity & $V p$ & $2530 \mathrm{~m} \mathrm{~s}^{-1}$ \\
$S$-wave velocity & $V S$ & $1220 \mathrm{~m} \mathrm{~s}^{-1}$ \\
\hline
\end{tabular}

zone with $s_{m}=1 \mathrm{~m}$ was used in the model and in the upper right zone embedding the fracture (Fig. 6b), respectively. Considering the criterion that the minimum wavelength $\lambda_{\min }=10 s_{m}$ to ensure correct wave propagation (Moser et al. 1999), the maximum frequency is around $120 \mathrm{~Hz}$ in the refined zone and $30 \mathrm{~Hz}$ in the other part of the model. Three hundred ambient vibration sources were randomly placed around the upper zone as punctual forces in the medium (Fig. 6a) and simultaneously triggered. The source is a $660 \mathrm{~s}$ long eye-shaped random signal with a near-flat frequency spectrum between $1 \mathrm{~Hz}$ and $30 \mathrm{~Hz}$ (Figs $6 \mathrm{c}$ and d).

Ambient vibrations (along the $y$ vertical and $x$ horizontal axes) were simulated at two points located at the column top $(S 1)$ and on the mass $(S 2), 2 \mathrm{~m}$ and $10 \mathrm{~m}$ back of the cliff edge, respectively (Fig. 7a). As expected, the simulated seismic motion excites the column at a frequency $f_{0}$, the maximum horizontal displacement being recorded at its top (Fig. 7a). The Fourier spectrum of the horizontal component $H_{1}(f)$ and the spectral ratios $H_{1}(f) / V_{1}(f)$ and $H_{1}(f) / H_{2}(f)$ are shown in Figs 7(b)-(d), respectively. In the following, the two spectral ratios will be referred to as $H / V$ and $H / H$ for the sake of simplicity. The five retrieved seismic noise parameters are the frequency of the first peak visible on the three graphs $\left(f_{0 H}, f_{0 H / V}, f_{0 H / H}\right)$ and the corresponding maximum amplitudes of the spectral ratios $\left(A_{H / V}\right.$ and $\left.A_{H / H}\right)$. The three values $\left(f_{0 H}, f_{0 H / V}, f_{0 H / H}\right)$ were found identical $\left(f_{0}=4.9 \mathrm{~Hz}\right)$ during all the tests, leading to the three dynamic parameters $\left(f_{0}, A_{H / V}\right.$ and $\left.A_{H / H}\right)$ to study. Modal analysis showed that the first peak frequency $f_{0}$ is the fundamental frequency of the column.

In order to compute stable values of the three parameters $\left(f_{0}\right.$, $A_{H / V}$ and $A_{H / H}$ ), numerical tests were performed to tune the following modelling parameters: the mesh size $s_{m}$, the number of sources $(n s)$, the time step $(d t)$ and the time of simulation $(t s)$. Considering a $4 \mathrm{~m}$ meshing over the whole model led to computation times longer than $8 \mathrm{hr}$ on a laptop. As we are modelling ambient vibrations and not specific seismic events, the size of the mesh in the remote area was increased. No noticeable difference has been observed between the computed spectral curves when increasing the mesh size $s_{m}$ until $20 \mathrm{~m}$. This value has been used in the computation, enabling to decrease the computation time to less than $4 \mathrm{hr}$. In a second step, we studied the influence of the parameters $n s, d t$ and $t s$. The stability (less than 5 per cent variation in $f_{0}$ values) was reached for the following values: $n s \geq 300, d t \leq 0.004 \mathrm{~s}$ and $t s \geq 360 \mathrm{~s}$. These three values are considered in all the performed simulations. The simulation time ts was increased (up to $660 \mathrm{~s}$ ) for some models in order to ensure the correctness of the computations down to half the column natural frequency $\left(f_{0} / 2\right)$, respecting the rule $t s=$ $1000 / f_{\min }$ proposed by different authors (e.g. Michel et al. 2008). The reliability of our simulations was checked by comparing the peak frequencies observed on spectral curves with the theoretical resonance frequencies computed using the modal approach implemented in the software Comsol. The three spectral curves computed from seismic noise records (Figs $7 b-d$ ) show two peaks at about 4.9 and $22 \mathrm{~Hz}$, which were found to correspond to the fundamental 
(a)

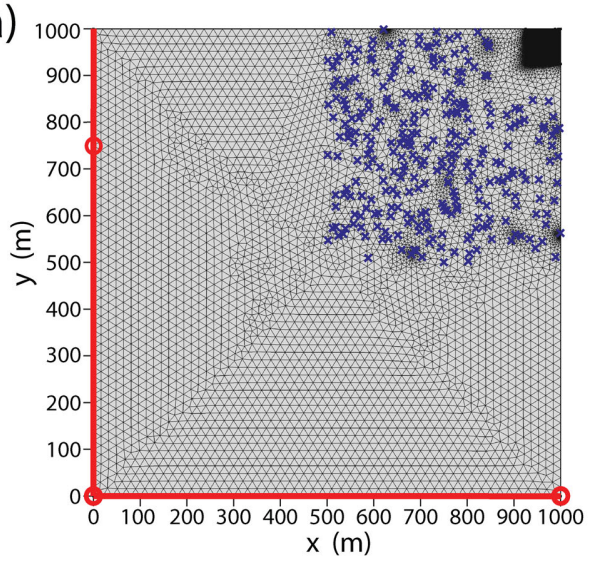

(b)

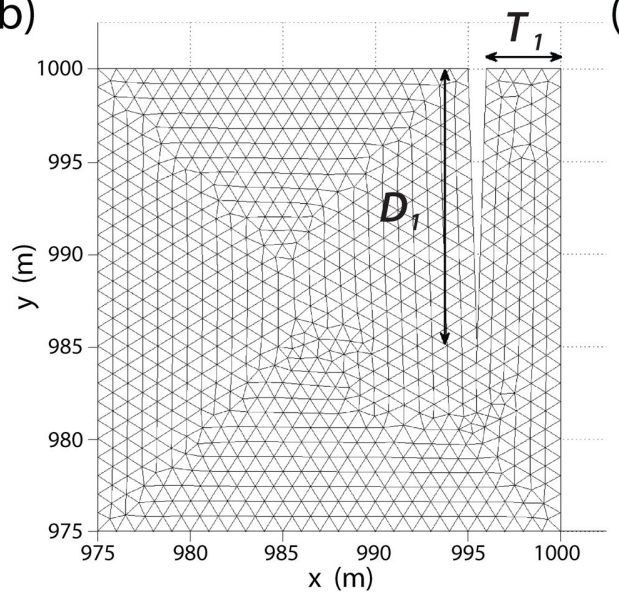

(c)

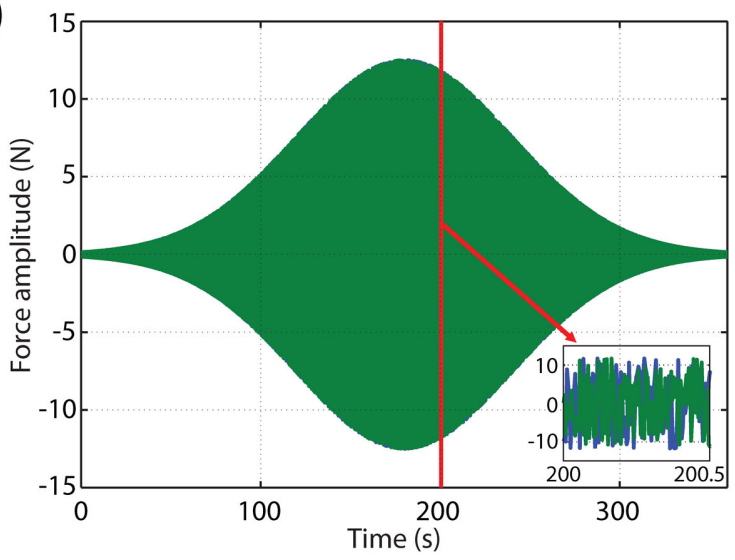

(d)

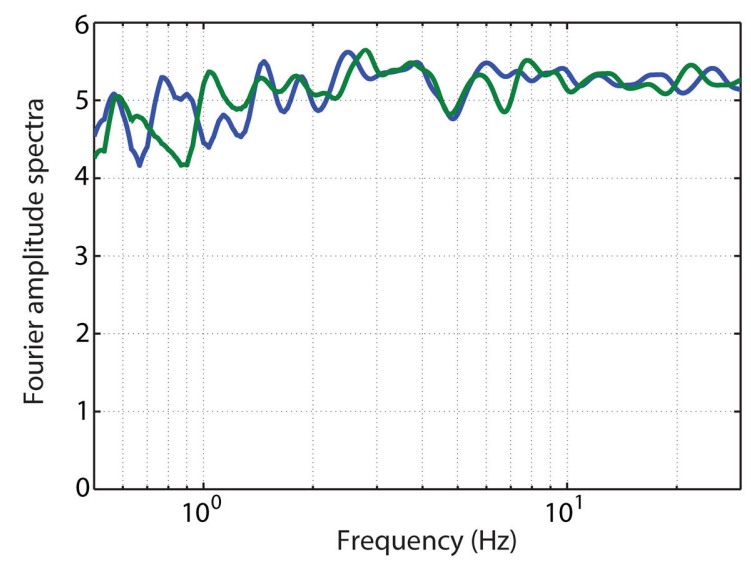

Figure 6. 2-D Numerical modelling of seismic noise. (a) Model meshing with source location (blue crosses) and absorbing boundaries (red lines). The refined zone is a square of $40 \mathrm{~m}$ size. (b) Enhanced view $(25 \mathrm{~m} \times 25 \mathrm{~m})$ of the upper right refined zone showing the fracture of depth $D_{1}$ decoupling a column of thickness $T_{1}$. (c) Source force signals along the horizontal (green) and vertical (blue) axes. The inset shows a detailed view over $0.5 \mathrm{~s}$. (d) The corresponding spectra in the $0.5-30 \mathrm{~Hz}$ frequency range.

mode and the first higher mode, respectively, with a difference less than 1 per cent. Finally, all the computations were made assuming the material to be elastic without damping, although rock and soil exhibit wave attenuation (e.g. Rix et al. 2000). We tested the influence of attenuation on the three dynamic parameters by introducing a Rayleigh damping, a convenient way of accounting for damping in numerical models (Semblat 1997). We considered a near-constant damping coefficient of 5 per cent on the frequency band [1-10 Hz], close to the maximum possible value in the near-surface rocks (Toksoz et al. 1979). The results, shown in Appendix B (Fig. B1), indicate that the three parameters derived from seismic noise are little affected by the damping in the considered frequency range, allowing the computations to be made in the elastic domain.

\subsection{Parametric modelling study}

The approximate geometry of Les Arches site $\left(T_{1}=4 \mathrm{~m}\right.$ and $D_{1}=15 \mathrm{~m}$ ) and the dynamic characteristics given in Table 1 were taken as a reference model. Modelling results (shown in Fig. 7) yields a fundamental frequency of $4.9 \mathrm{~Hz}$ with maximum amplitudes $A_{H / V}=19$ and $A_{H / H}=31$ for the two spectral ratios $H / V$ and $H / H$, respectively. The location of the reference point $S 2$ on the rock mass (displaced from $10 \mathrm{~m}$ to $20 \mathrm{~m}$ and $35 \mathrm{~m}$ back to the cliff edge) does not affect the values of $A_{H / H}$ and $f_{0}$ (Fig. 7d). Additional numerical simulations were performed in order to test the sensitivity of dynamic parameters to the column geometry, by varying $D_{1}$ and $T_{1}$ around the reference values. A total of 54 temporal finite element simulations were made to evaluate the influence of column characteristics on the dynamic parameters, combining variations in $D_{1}$ ( 6 values between 5 and $25 \mathrm{~m}$ ), in $T_{1}(2,4$ and $6 \mathrm{~m}$ ), in Young's modulus $E$ (2, 10 and $20 \mathrm{GPa})$ and keeping constant the density and the Poisson's coefficient. The results are given in Table $\mathrm{C} 1$ of Appendix C.

First, the $H / V$ and $H / H$ curves are shown in Figs 8(a) and (b), respectively, for the fracture depth $D_{1}$ varying between $5 \mathrm{~m}$ and $25 \mathrm{~m}$, keeping constant all the other model characteristics. It can be seen that the increase in $D_{1}$ induces a regular decrease in resonance frequency, associated to an augmentation of the amplitudes $A_{H / V}$ and $A_{H / H}$. Using the simple relation

$f_{0}=\frac{1}{2 \pi} \sqrt{\frac{K}{M}}$

which corresponds to the fundamental frequency of an oscillator of mass $M$ and rigidity $K$, this frequency drops with $D_{1}$ is explained by both the increase of the column mass and the decrease of its rigidity, while the increase in amplitude is probably controlled by the decrease in rigidity. For a slender beam of thickness $T_{1}$ in 
(a)

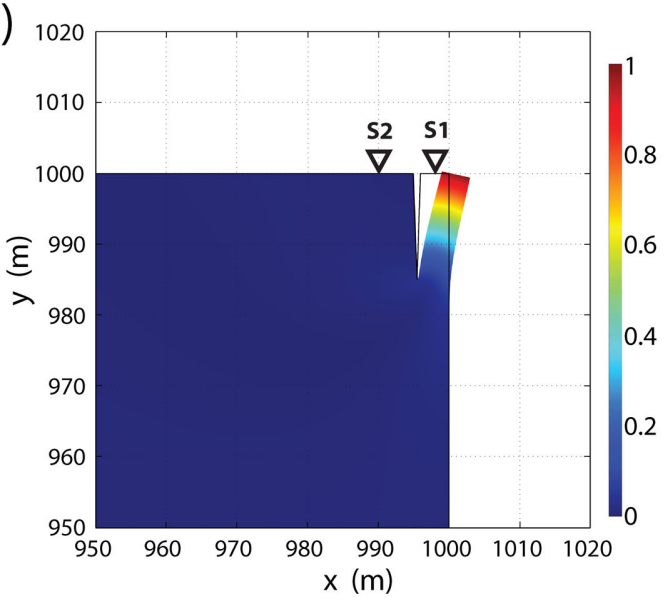

(c)

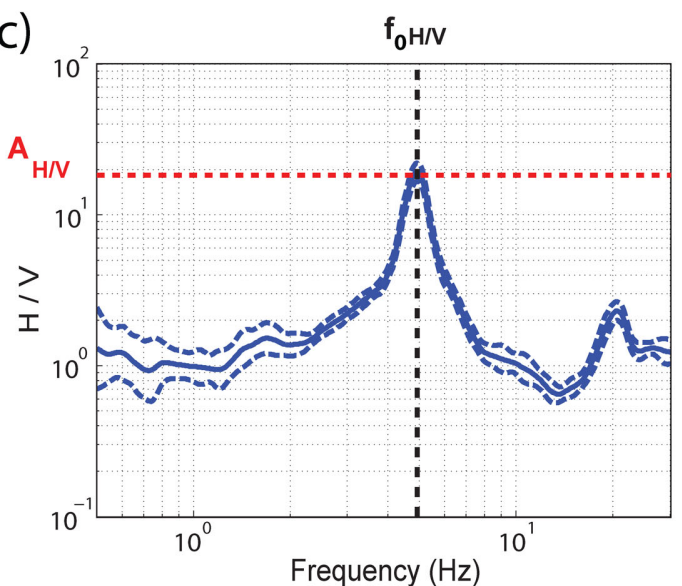

(b)

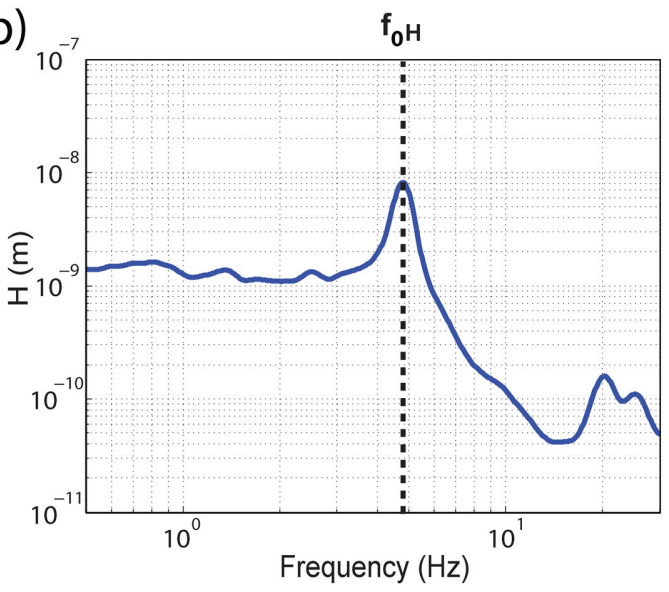

(d)

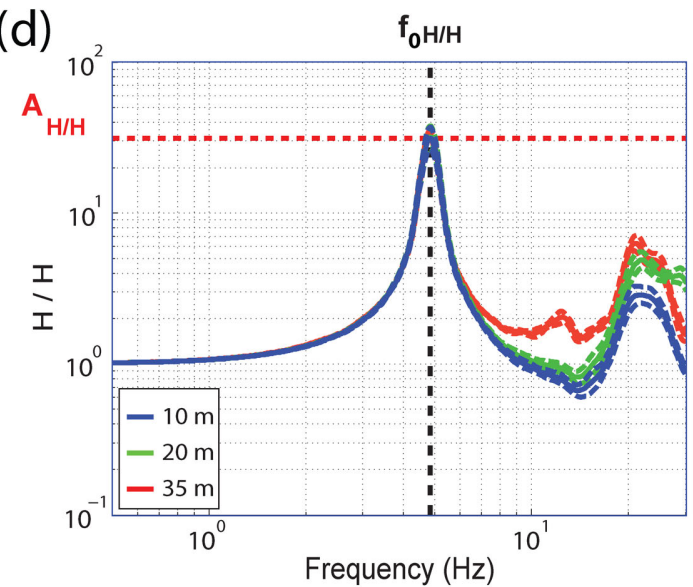

Figure 7. Numerical modelling of the column response for the reference case $\left(T_{1}=4 \mathrm{~m} ; D_{1}=15 \mathrm{~m} ; E=10 \mathrm{GPa}\right)$ and definition of the five parameters derived from seismic noise. (a) Maximum amplitude displacement of the column for the fundamental mode. (b) Spectral amplitude of the $H_{1}$ component (parameter $f_{0 H}$ ). (c) $H / V$ spectral ratio at sensor $S 1$ (parameters $f_{0 H / V}$ and $A_{H / V}$ ). (d) $H / H$ spectral ratio (parameters $f_{0 H / H}$ and $A_{H / H}$ ). The $H / H$ curve is shown for three distances of $S 2$ from the cliff edge (10,20 and $35 \mathrm{~m})$.

flexural vibration, the natural frequencies are given by the following equation (Chen \& Lui 1997):

$f_{n}=\frac{k_{n}^{2}}{2 \pi} \frac{T_{1}}{D_{1}^{2}} \sqrt{\frac{E}{12 \rho}}$,

where the coefficient $k_{n}$ defines the resonant mode at frequency $f_{n}$ ( $k_{0}=1.875$ for the fundamental frequency $f_{0}$ ). The values of $f_{0}$ given by this equation are compared to the numerical results in Figs 8(c) and (d), where $f_{0}$ is plotted as a function of $T_{1} / D_{1}{ }^{2}$. In Fig. 8(c), the curves computed for the three values of $T_{1}(2,4$ and $6 \mathrm{~m})$ and $E=10 \mathrm{GPa}$ are tangent to the theoretical line (eq. 2) for low values of $T_{1} / D_{1}{ }^{2}$ (i.e. when the column slenderness is high). The same tendency is observed in Fig. 8(d) when the Young's modulus $E$ is varied with $T_{1}=4 \mathrm{~m}$. On both figures, $f_{0}$ at high $T_{1} / D_{1}{ }^{2}$ values are lower than those predicted by eq. (2).

On the basis of eq. (2), we then looked for general equations of the form

$\mathrm{DP}=a T_{1}^{b} D_{1}^{c} E^{d}$

relating the dynamic parameters DP $\left(f_{0}, A_{H / V}\right.$ and $\left.A_{H / H}\right)$ retrieved from seismic noise to the column characteristics $\left(T_{1}, D_{1}\right.$ and $E$ ), using the 54 numerical models. The least-square solution for the coefficients $a, b, c$ and $d$ are given in Table 2 .
A very good fit was found for all dynamic parameters (correlation coefficient CC >0.97):

$f_{0}=44.696 T_{1}^{0.486} D_{1}^{-1.507} E^{0.49}$.

For $f_{0}$, the coefficient $d$ is close to 0.5 , in agreement with eq. (2), while the coefficients $b$ and $c$ are significantly different from 1 and -2 , respectively, explaining the deviation from the theoretical line in Figs 8(c) and (d).

For the parameters $A_{H / V}$ and $A_{H / H}$, the coefficient $d$ is very low (around 0.015 ) indicating that the modulus $E$ has little control on these parameter variations. For $A_{H / H}, b$ and $c$ are of the same order of magnitude ( 0.64 and 0.67$)$, with opposite sign. This strongly suggest a slenderness control $\left(D_{1} / T_{1}\right)$ on this parameter. Assuming that $b=-c$ and $d=0$ for $A_{H / H}$ and $A_{H / V}$, we obtained the following two equations:

$A_{H / V}=5.436\left(T_{1} / D_{1}\right)^{-0.906}$

$A_{H / H}=13.49\left(T_{1} / D_{1}\right)^{-0.658}$

with correlation coefficients $\mathrm{CC}$ of 0.95 and 0.97 , respectively (Table 2). Although the correlation coefficient for $A_{H / V}$ is slightly lower when imposing $b=-c$ (Table 2), eqs (5) and (6) were considered in the following for the sake of simplicity and applicability. 
(a)

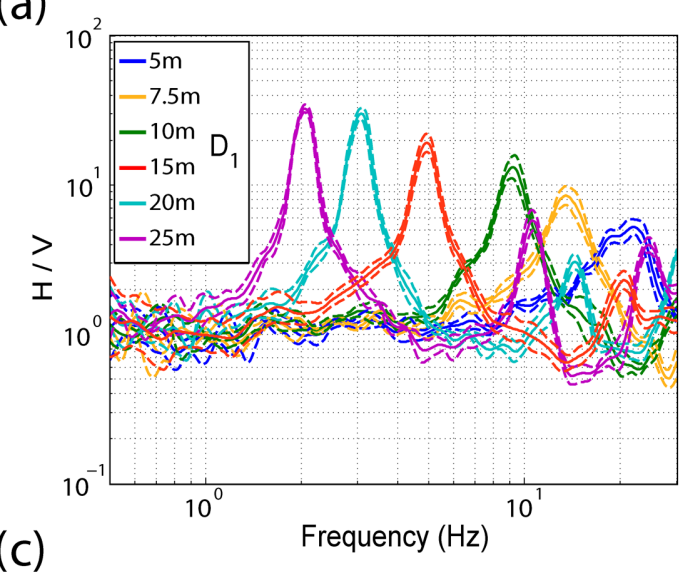

(c)

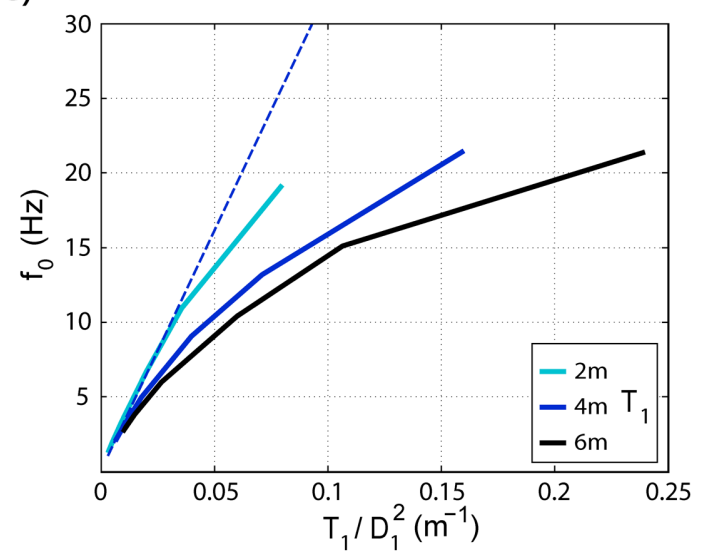

(b)

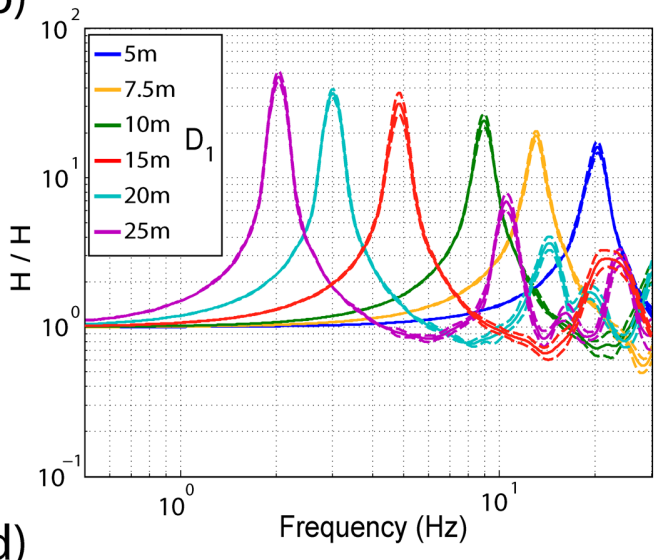

(d)

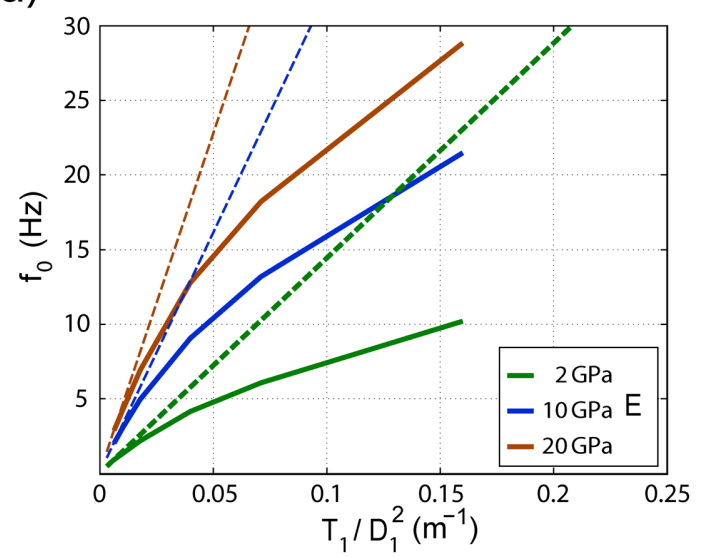

Figure 8. Variations of the noise spectral characteristics with the column geometry. The dynamic properties are given in Table 1. (a,b) Variations of the spectral ratios $H / V$ and $H / H$ with the fracture length $D_{1}$ (from 5 to $25 \mathrm{~m}$ ) for a column thickness $T_{1}$ of 4 m. (c) Resonance frequency $f_{0}$ as a function of $T_{1} / D_{1}{ }^{2}$. (d) Resonance frequency $f_{0}$ as a function of $T_{1} / D_{1}{ }^{2}$. The theoretical frequency for a slender beam (eq. 2) is shown with a dashed line.

Table 2. Values of the coefficients $a, b, c$ and $d$ in the equation DP $=$ $a T_{1}^{b} D_{1}^{c} E^{d}$, where DP is one of the dynamic parameters $\left(f_{0}, A_{H / V}\right.$ and $\left.A_{H / H}\right)$ and $T_{1}, D_{1}$ and $E$ are the thickness, the depth and the Young's modulus of the column, respectively. The coefficients $a, b, c$ and $d$ were determined by least-square fitting the equation (in $\log$ ) to the 54 numerical data set given in Appendix C. CC is the Correlation Coefficient. The numbers in italic correspond to the coefficients computed when imposing $c=-b$ and $d=0$.

\begin{tabular}{lccccc}
\hline Dynamic parameter (DP) & $a$ & $b$ & $c$ & $d$ & CC \\
\hline$f_{0}(\mathrm{~Hz})$ & 44.696 & 0.486 & -1.507 & 0.490 & 0.997 \\
$A_{H / V}$ & 2.513 & -0.631 & 1.088 & -0.016 & 0.980 \\
& 5.436 & -0.906 & 0.906 & 0 & 0.950 \\
$A_{H / H}$ & 13.389 & -0.641 & 0.667 & -0.015 & 0.973 \\
& 13.490 & -0.658 & 0.658 & 0 & 0.972 \\
\hline
\end{tabular}

The three parameters $\left(f_{0}, A_{H / V}\right.$ and $\left.A_{H / H}\right)$ are plotted in log scale as a function of the inverse of slenderness $\left(T_{1} / D_{1}\right)$ in Fig. 9. As expected, the $f_{0}$ data are scattered (Fig. 9a) while the $A_{H / V}$ and $A_{H / H}$ data (Figs 9b and c) show a linear decrease with $T_{1} / D_{1}$. The two lines (eqs 5 and 6 ) with \pm one standard deviation interval are drawn in Figs 9(b) and (c). These results suggest that the spectral ratio amplitudes are mainly controlled by the $T_{1} / D_{1}$ ratio and that these theoretical relations could then be applied on real data to estimate the slenderness of a potentially unstable column. If the rear column thickness $T_{1}$ can be measured in the field, the fracture depth $D_{1}$ can be directly assessed. In contrast, $f_{0}$ does not exhibit such a simple dependency on the slenderness (Fig. 9a, eq. 4). These theoretical results relating the dynamic parameters to the geometric and mechanical characteristics of the column are now applied to the two sites exhibiting cliff geometry.

\section{COMPARISON BETWEEN SIMULATED AND MEASURED RESPONSES}

The geometric and dynamic characteristics of the two sites (Les Arches and Bory), as well as the three parameters $\left(f_{0}, A_{H / V}\right.$ and $\left.A_{H / H}\right)$ measured from ambient vibrations are synthesized in Table 3. The presented $E$ (Young's Modulus), $V p$ and $V S$ ( $P$-wave and $S$-wave velocities) values are averages of the in situ measured dynamic characteristics. These values are significantly different at the two sites. The column at the Bory site exhibits a much lower resonance frequency $\left(f_{0}=2.85 \mathrm{~Hz}\right)$ than that at Les Arches site $\left(f_{0}=6.2 \mathrm{~Hz}\right)$, in agreement with the much lower rigidity of the volcanic rocks ( $E=2 \mathrm{GPa})$ compared to limestone $(E=10 \mathrm{GPa})$. As mentioned before, the Bory site also exhibits $A_{H / V}$ values higher than $A_{H / H}$ values, in contrast with the other site and the modelling results (see Figs 9e and f).

The values of the parameters $\left(f_{0}, A_{H / V}\right.$ and $\left.A_{H / H}\right)$ measured at the two sites are compared to the theoretical curves derived from the numerical modelling in Figs 9(d) to (f). At Les Arches site, the measured $f_{0}$ yields a mean theoretical $T_{1} / D_{1}$ value of $0.34(0.33-$ 0.35 , considering uncertainty) (Fig. $9 \mathrm{~d}$ ). With a column thickness of $T_{1}=4.5 \mathrm{~m}$, the rear fracture depth $D_{1}$ is estimated to be about $13 \mathrm{~m}$, a value comparable to the one obtained from the outcrop observation (15 m). Using the two mean ratio amplitude parameters 
(a)

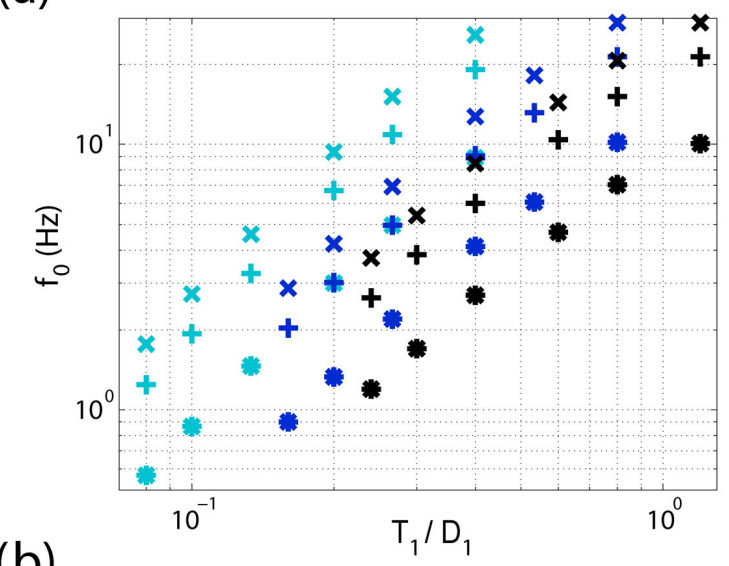

(b)

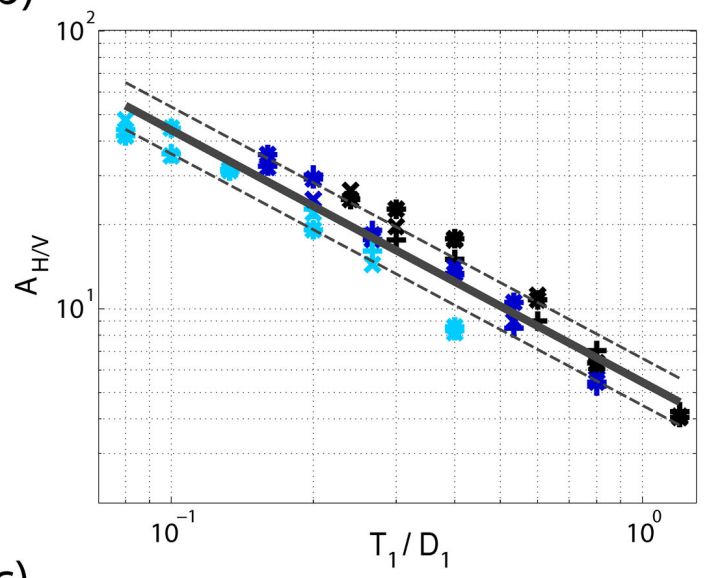

(c)

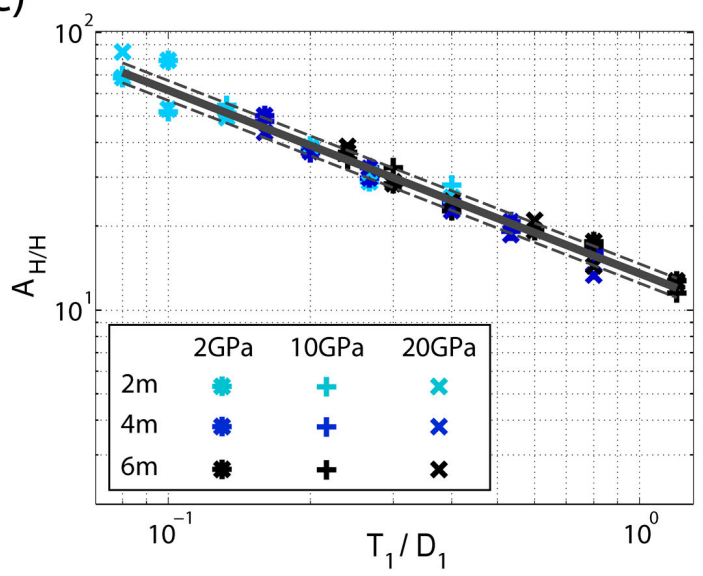

(d)

(e)
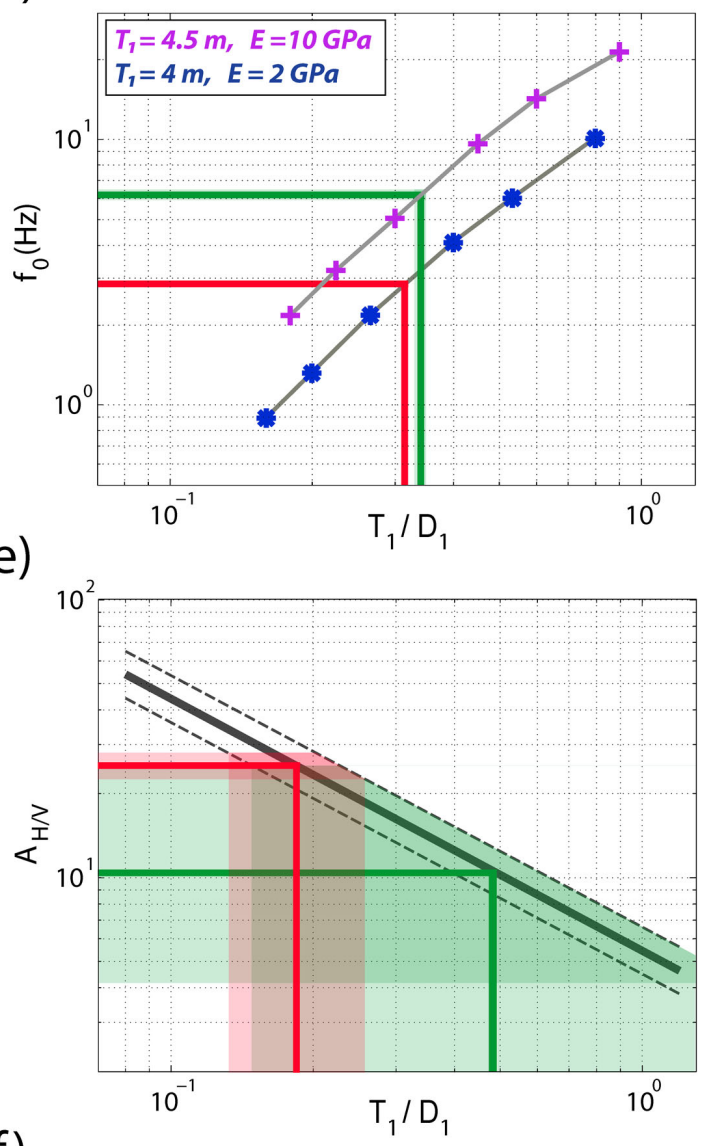

(f)

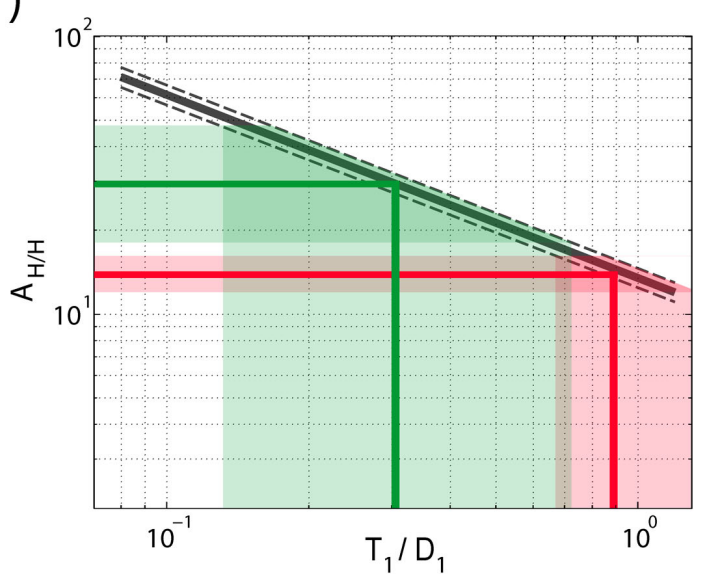

Figure 9. (a-c) Variations of the parameters $f_{0}, A_{H / V}$ and $A_{H / H}$ as a function of $T_{1} / D_{1}$ for three values of $T_{1}\left(2,4\right.$ and $6 \mathrm{~m}$ ), six values of $D_{1}$ (from 5 to $25 \mathrm{~m}$ ) and three values of Young's modulus $E(2,10$ and $20 \mathrm{GPa})$. The equations of the lines are given in the text. (d-f) Comparison between the three measured parameters $\left(f_{0}, A_{H / V}\right.$ and $\left.A_{H / H}\right)$ and the theoretical curves (dark grey) shown in panels (a)-(c). The mean measured parameters are given with their variation range (green and red colours for the Les Arches and Bory sites, respectively).

$\left(A_{H / V}\right.$ and $\left.A_{H / H}\right)$ yields $T_{1} / D_{1}$ values of $0.47(0.15-1.65)$ and 0.3 (0.13-0.72), respectively, providing $D_{1}$ estimations of 10 and $15 \mathrm{~m}$. The three dynamic parameters provide similar $D_{1}$ values, which are close to the observation. However, the $A_{H / V}$ and $A_{H / H}$ are less reliable, due to the large scattering of the measured values.

At the Bory site, $T_{1} / D_{1}$ is estimated to about $0.315(0.31-0.32)$ from $f_{0}$ (Fig. 9d), leading to a column height $D_{1}$ of about $12 \mathrm{~m}$, again in agreement with the observed rear fracture depth (over $10 \mathrm{~m})$. In contrast, the well-constrained measured $A_{H / V}$ and $A_{H / H}$ values lead to a very different estimation of the $T_{1} / D_{1}$ value $(0.18$ and around 0.97 , respectively). This discrepancy results from the unexpected observation that $A_{H / V}$ is significantly higher than $A_{H / H}$ at this site (Figs 9e and f). A major characteristic distinguishes the Bory site from the more homogeneous Les Arches site: the existence of multiple rear fractures affecting the rock mass as far as $60 \mathrm{~m}$ from the cliff (Fig. 2c). The potential effect of multiple fracturing on the ambient vibrations is explored in the following section, using numerical simulations. 
Table 3. Characteristics of the column at the two sites ( $T_{1}$ : thickness; $D_{1}$ : fracture length; $E$ : Young's Modulus; $V p$ and $V s: P$-wave and $S$-wave velocities) and measured dynamic parameters ( $f_{0}$ : fundamental resonance frequency; $A_{H / V}$ : amplitude of the $H / V$ spectral ratio at frequency $f_{0} ; A_{H / H}$ : the same for the $H / H$ ratio). The mean and variation range (italic font) are given for the three parameters. $D_{1}$ values were estimated from outcrop observations while $T_{1}$ values were measured at the top surface. The dynamic characteristics $E$, $V p$ and $V s$ were estimated from the seismic prospecting performed at the two sites (Levy 2011; Bottelin 2014) considering a density of $2500 \mathrm{~kg} \mathrm{~m}^{-3}$ for the limestone (Les Arches) and $2200 \mathrm{~kg} \mathrm{~m}^{-3}$ for the volcanic rock at the Bory site.

\begin{tabular}{lccccccc}
\hline Site & $T_{1}(\mathrm{~m})$ & $D_{1}(\mathrm{~m})$ & $E(\mathrm{GPa})$ & $V p(V s)\left(\mathrm{m} \mathrm{s}^{-1}\right)$ & $f_{0}(\mathrm{~Hz})$ & $A_{H / V}$ & $A_{H / H}$ \\
\hline Les Arches & 4.5 & 15 & 10 & 2530 & 6.2 & 10.4 & 29.4 \\
& & & & $(1220)$ & $5.9-6.5$ & $4.2-25.3$ & $18.1-47.8$ \\
Bory & \multirow{2}{*}{4} & 2 & 1065 & 2.85 & 25.4 & 13.8 \\
& & & & $(600)$ & $2.8-2.9$ & $22.8-28.2$ & $12.0-16.2$ \\
\hline
\end{tabular}

\section{MULTIPLE FRACTURING SIMULATIONS}

The influence of the presence of two additional fractures of lengths $D_{2}$ and $D_{3}$ (see the geometry in Fig. 5) on the parameters $\left(f_{0}, A_{H / V}\right.$ and $A_{H / H}$ ) is now investigated. The objective is not to exactly fit the observations with modelling but to assess if this fracturing is likely to explain the observed discrepancy (Section 4) between the data and modelling results at the Bory site. A first model geometry with one fracture, considering a fracture depth $\left(D_{1}=13 \mathrm{~m}\right)$ derived from the resonance frequency $f_{0}=2.85 \mathrm{~Hz}$ and the dynamic parameters given in Table 3 , is set up. The comparison with the experimental data (Figs 10a and b) indicates that 1-fracture modelling explains the observed $A_{H / V}$ (around 25) but strongly overestimates the $A_{H / H}$ value (30 instead of 14 ). Introducing a second fracture $F_{2}$ (observed on the field) with the same depth $\left(D_{2}=13 \mathrm{~m}\right)$ at a distance $T_{2}=15 \mathrm{~m}$ from the first one, decreases the mean $A_{H / H}$ to a value of about 15, in agreement with the experimental data (Fig. 10b), while the $A_{H / V}$ remains almost unchanged. Motion analysis showed that this $A_{H / H}$ decay results from the vibration of the column between fractures $F_{1}$ and $F_{2}$, which becomes significant when $D_{2}$ reaches the same value as $D_{1}$ (see Fig. D1 in Appendix D). In contrast, the introduction of a third fracture $F_{3}$ with the same depth $\left(D_{3}=13 \mathrm{~m}\right.$; $\left.T_{3}=15 \mathrm{~m}\right)$ does not significantly affect the values of the three dynamic parameters (Figs 10a and $\mathrm{b}$ ).

The effect of a deep third fracture $\left(D_{3}=26\right.$ and $\left.39 \mathrm{~m}\right)$ is studied and the mean theoretical and experimental $H / V$ and $H / H$ curves are compared for the sensors $S 1$ and $S 2$ nearest the cliff in Figs 10(c) and (d). A striking feature is that the introduction of a deep third fracture $F_{3}$ generates a $H / V$ peak $(\approx 5)$ at low frequency $(1.8 \mathrm{~Hz})$ (Fig. 10c). Modal analysis pointed out that this peak results from the resonance of the whole mass located between $F_{3}$ and the cliff. The experimental data at sensors $S 1$ and $S 2$ are compared to the modelling results $\left(D_{3}=26 \mathrm{~m}\right)$ in Figs $10(\mathrm{e})$ and (f), considering the standard deviations. The $A_{H / H}$ and $A_{H / V}$ amplitudes are correctly retrieved by modelling. In addition, the introduction of a third deep fracture generates a slight bump at low frequency on both sensors, however with a lower amplitude and over a narrower range than that observed. The modelling performed in this study is limited in size and frequency and it does not simulate the real fracturing of the Bory crater, which includes more remote and probably deeper fractures. The modelling results however suggest the presence of at least one remote deep fracture. A striking discrepancy between experimental and numerical spectral ratio curves is the through found around $6 \mathrm{~Hz}$ in all 2-D simulations (see Fig. 10). This through may only exist on 2-D numerical curves because other resonance modes excite the 3-D column. This hypothesis was tested with a 3-D numerical modal analysis of the Bory column, assuming a 20-m-column width (Appendix E; Fig. E1). The modal analysis in- dicates the existence of a second torsion mode at $4.77 \mathrm{~Hz}$ and a third bending mode (parallel to the cliff) at $5.73 \mathrm{~Hz}$. The existence of these two modes, close to $6 \mathrm{~Hz}$ and which cannot be considered with 2-D modelling, may explain the discrepancy between experimental and 2-D numerical results. In contrast, the experimental curves exhibit a moderate peak around $8 \mathrm{~Hz}$. The spectral polar plot (Fig. 4a) indicates that this vibration mode is not exactly perpendicular to the cliff. Moreover, the high frequency part of the spectral ratios is more sensitive to the signal duration, as suggested by the difference observed between 45 min and $3 \mathrm{~d}$ records (Figs 4 e and $\mathrm{h}$, comparison between the $H / H$ curves).

\section{DISCUSSION}

2-D Numerical modelling of a homogeneous cliff affected by fractures has identified three dynamic parameters $\left(f_{0}, A_{H / V}\right.$ and $\left.A_{H / H}\right)$ that can be derived from continuous noise records using two 3-C sensors. A major result of the modelling (Fig. 9) is that the two ratio amplitude parameters $A_{H / V}$ and $A_{H / H}$ appear to be only controlled by the slenderness $D_{1} / T_{1}$ of the column (or its inverse $T_{1} / D_{1}$ ). Measuring $A_{H / V}$ and $A_{H / H}$ could then be used to obtain the fracture depth $D_{1}$, if the rear fracture is observed in the field. In contrast, using $f_{0}$ to derive $D_{1}$ requires the mechanical property (Young's modulus) of the rock, making this parameter a priori less attractive. These conclusions have however to be tempered by the two applications presented in this paper. On the first site (Les Arches), the two ratio amplitude parameters turned out to be very variable, with time fluctuations seeming to be controlled by wind conditions. The effect of wind on some seismic noise parameters has been mentioned before, both for measurements on sites and buildings. On sites, the guidelines following the Sesame project (SESAME 2004) recommended to avoid recording near structures like buildings and trees during strong winds and to protect the sensors. The effect of the wind on the $H / V$ curve is however still an object of debate (e.g. Guillier et al. 2007). On buildings, some authors observed an effect of the wind on the resonance frequency (e.g. Clinton et al. 2006) but there are still not enough data to understand the exact link between wind and frequency variation (Mikael et al. 2013). The observed effect of wind on $H / V$ and $H / H$ curves at Les Arches site remains an open question. However, considering the mean values of $A_{H / V}$ and $A_{H / H}$ during weak-wind periods provides reasonable and consistent estimates of $D$. On the other site (Bory), $A_{H / H}$ was found to be lower than $A_{H / V}$, an observation which disagrees with the one-fracture modelling results. Numerical modelling showed that additional remote fractures did not affect the $A_{H / V}$ amplitude but significantly decreased the $A_{H / H}$ amplitude (by a factor of two), explaining the apparent discrepancy. However, these results have been obtained by making three assumptions: (1) the geometry of the cliff is 2-D, 
(a)

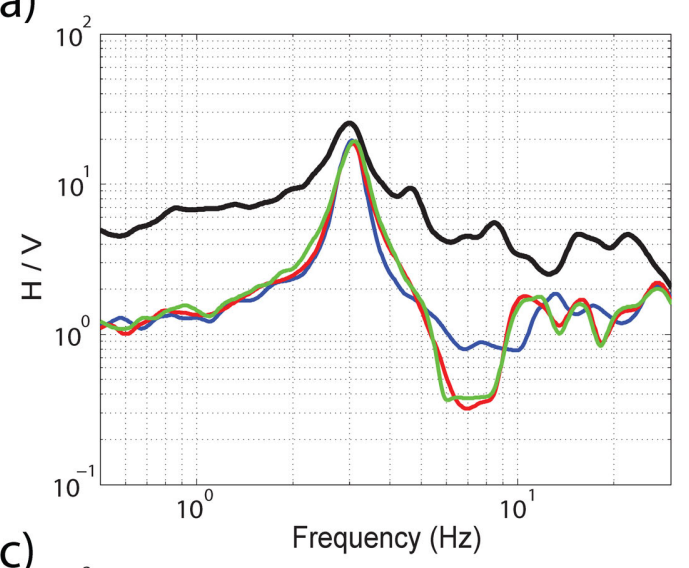

(c)

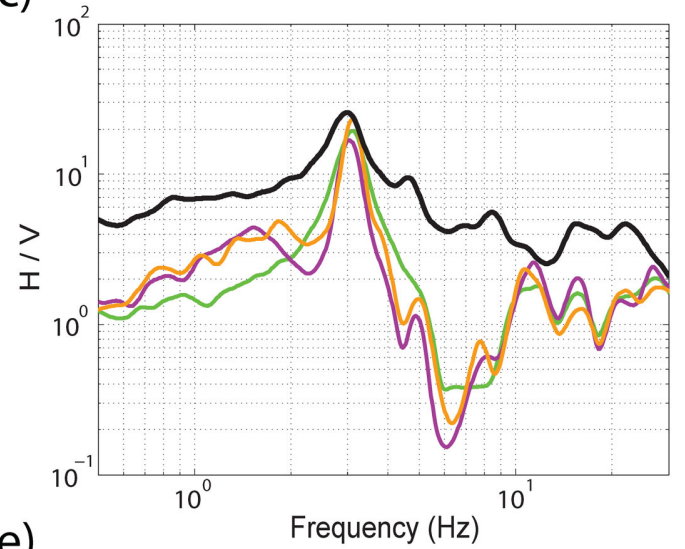

(e)

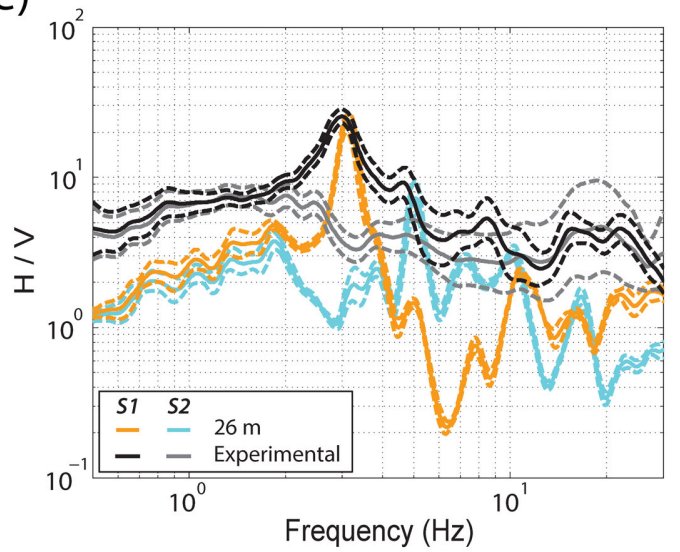

(b)

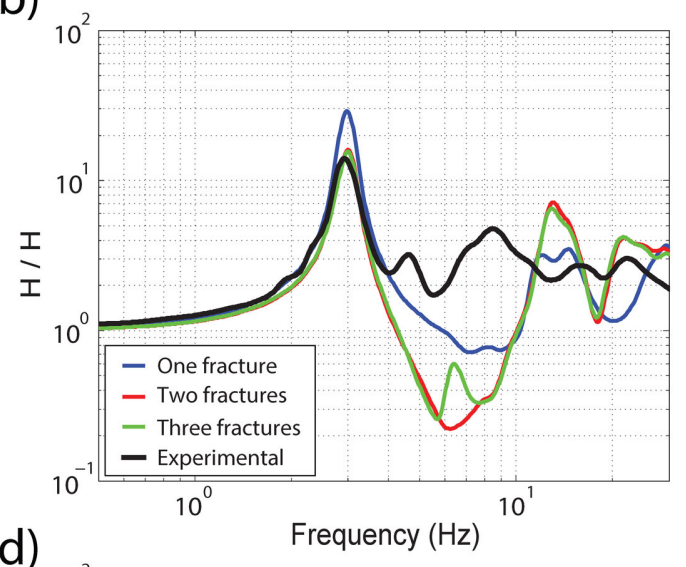

(d)

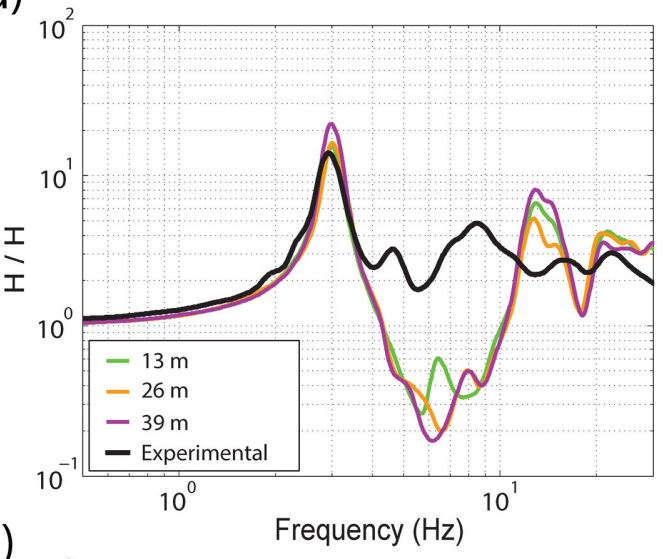

(f)

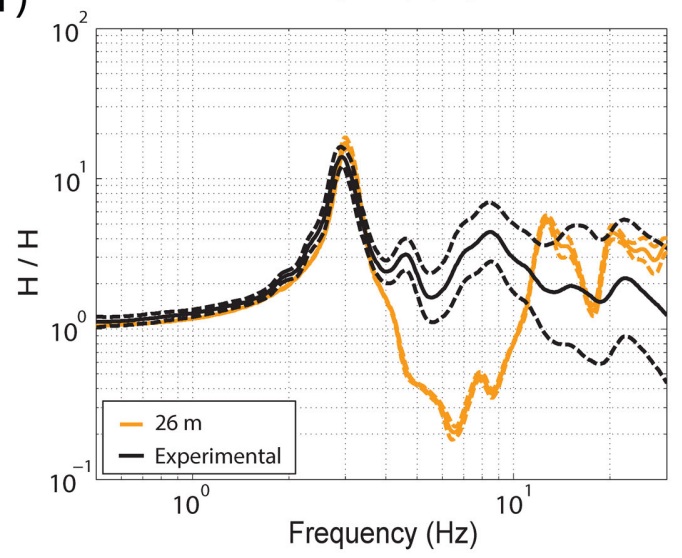

Figure 10. Effect of multiple fracturing at the Bory site. Comparison between numerical modelling results and experimental data. (a,c,e) $H / V$ curves. (b,d,f) $H / H$ curves. (a,b) Comparison for a geometry with one, two and three fractures (same depth $D=13 \mathrm{~m}$ ) at sensor $S 1$. (c,d) Comparison for three fractures with a varying depth $D_{3}=13,26$ and $39 \mathrm{~m}$ at sensor $S 1$. (e,f) Comparison between the three-fracture geometry modelling $\left(D_{1}=13 \mathrm{~m}, D_{2}=13 \mathrm{~m}\right.$ and $\left.D_{3}=26 \mathrm{~m}\right)$ and experimental data for the sensors $S 1$ and $S 2$. Plain lines are mean curves and dashed lines represent \pm one standard deviation around the mean.

(2) the cliff is homogeneous and (3) the main rupture mechanism is toppling, associated with a progressive downward breaking of rock bridges. The first assumption implies that the first identified resonance frequency $f_{0}$ corresponds to the bending mode with a motion perpendicular to the cliff. We performed 3-D modal analysis on a cuboid column (of depth $D_{1}$, thickness $T_{1}$ and width $w$ ), varying $w$. The fundamental frequency of the bending mode perpendicular to the cliff remains equal to that computed in 2-D, as long as the width $w$ is larger than the thickness $T_{1}$. In the two applications presented in this paper, this condition is fulfilled with $w / T_{1}$ ratios over 2 . An additional 3-D effect may arise from a variation in fracture depth $D_{1}$ along its width $w$. We tested the influence of this variation, fixing $D_{1}$ in the middle of the fracture and varying the fracture-bottom dip $\alpha$ from $0^{\circ}$ to $30^{\circ}$. Modal analysis results (Table E1; Appendix E) show that such dip variation yields a frequency change of only 5 per cent for the fundamental mode $\left(f_{0}\right)$, highlighting that the 2-D approximation is robust for assessing an order of magnitude of the fracture depth. The second assumption of homogeneity is obviously not met in the Bory site where a $4 \mathrm{~m}$ thick scoria layer is interbedded in the basalts (Fig. 2e). We modelled the effect of this low rigidity layer (Appendix F; Fig. F1) with one, two and three fractures, assuming a Young's modulus of $0.85 \mathrm{GPa}$. The main effect of the scoria layer is to decrease the resonance frequency, with unclear effect on the $A_{H / H}$ and $A_{H / V}$ values. Given the uncertainty on the dynamic 
(a)

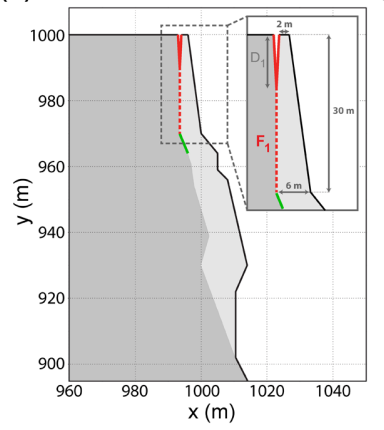

(b)

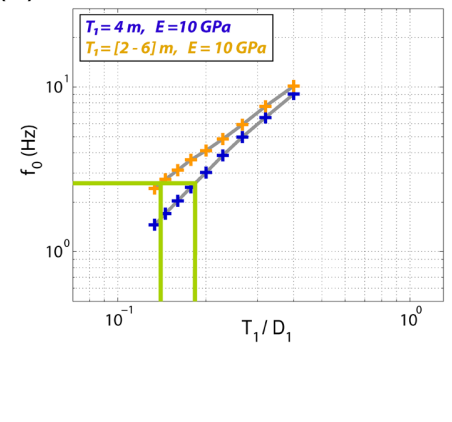

Figure 11. Chamousset site. (a) Vertical cross-section showing the column geometry (light grey) with the upper $30 \mathrm{~m}$ high vertical fracture. The main $6 \mathrm{~m}$ thick rock bridge is shown in green. (b) Estimation of the ratio $T_{1} / D_{1}$ from the resonance frequency $f_{0}$ measured before failure (Levy et al. 2010) for a rectangular column (blue crosses) and for a trapezoidal column (orange crosses). See the text for details.

parameters in the basalt and scoria layers, it is impossible to assess the real influence of the scoria layer at this stage, but its effect on the low measured $A_{H / H}$ values cannot be ruled out. These results stress out the complex interaction between fracturing, layering and the dynamic parameters derived from seismic noise, which explains the discrepancy in $T_{1} / D_{1}$ values obtained in the Bory site (see Fig. 9). With regards to the third hypothesis, we tested the approach proposed in this paper against the data available before the collapse of the $21000 \mathrm{~m}^{3}$ column at the Chamousset site (Vercors massif; Levy et al. 2010), located $100 \mathrm{~m}$ from Les Arches site. The natural frequency $f_{0}$ exhibited a significant drop (from 3.4 to $2.6 \mathrm{~Hz}$ ) in the weeks before the fall, resulting from the breakage of rock bridges as attested by the increase in seismic activity measured on the vertical sensors and field observation (Levy et al. 2011). Unfortunately, the acquisition system stopped working two weeks before the fall, preventing to have the $f_{0}$ value just before the rupture. The column that crashed down was about $90 \mathrm{~m}$ high, $30 \mathrm{~m}$ wide, and 2-10 m thick (Fig. 11a).

The failure surface was a nearly perfect vertical plane for $30 \mathrm{~m}$, while the rest of the scar presented an overall positive tilt. The main zone showing evidence of fresh rock rupture was an elongated horizontal area corresponding to a $6 \mathrm{~m}$ thick limestone bed located $30 \mathrm{~m}$ below the plateau. Assuming the same Young's modulus as for Les Arches site $(10 \mathrm{GPa})$ and a mean thickness of $4 \mathrm{~m}$, we obtain a $T_{1} / D_{1}$ value of 0.17 for $f_{0}=2.6 \mathrm{~Hz}$ and a fracture depth $D_{1}$ estimated to $24 \mathrm{~m}$ (Fig. 11b). Over the first $30 \mathrm{~m}$, the column has however the shape of a right-angled trapezoid with an upper base of $2 \mathrm{~m}$ and a lower base of $6 \mathrm{~m}$. A more accurate modal analysis accounting for the trapezoidal shape gives $D_{1}=28 \mathrm{~m}$ (Fig. 11b). These two values are consistent with the fracture depth $(30 \mathrm{~m})$ down to the main rock bridge area, with a better estimate for the trapezoidal shape. It must be stressed out that this method provides an order of magnitude of the open vertical fracture depth but does not give information on the coupling state of the lower part of the scar.

Finally, the shape of the $H / V$ curve at low frequency could indicate some site amplification effects, as shown in the Bory site. The presence of a plateau-like shape (here in the range of $0.8-2.5 \mathrm{~Hz}$ ) on the $H / V$ curve has been previously observed in alluvial basins close to the edges where the geometry is 2-D or 3-D (e.g. Özalaybey et al. 2011; Le Roux et al. 2012). As all the $H / V$ curves measured in the Bory Crater exhibit a plateau-like shape, this feature could result from a 2-D or 3-D site effect due to the semi-elliptical shape

of the Bory Crater and could explain the remaining discrepancy between 2-D numerical modelling and observations (Fig. 10e).

\section{CONCLUSIONS}

This paper aimed to identify the pertinent and applicable parameters that could be extracted from ambient vibrations and used to gain information on a prone-to-fall column in stiff rock conditions. From numerical modelling, it was shown that the two ratio amplitude parameters $A_{H / V}$ and $A_{H / H}$ are mostly controlled by the inverse of the slenderness of the column $(T / D)$. In contrast, the first resonance frequency $f_{0}$ depends on both the column geometry and the rock Young's modulus $E$. This $T / D$ dependence, which allows the depth $D$ to be assessed if the thickness $T$ is known, could bring a key information about the column decoupling from simple seismic measurements. The study of two sites exhibiting a prone-to-fall column have however revealed that the application of these theoretical results might face some difficulties. The first one is the tremendous sensitivity of the ratio amplitude parameters to wind conditions at the first site. Although the mean parameters for weak wind conditions provided consistent results, the application of this method requires a thorough analysis of the data. On the second site, the seismic noise data did not match one-fracture modelling results because of the presence of multiple rear fractures located further in the Bory Crater, which significantly decreases the amplitude of the parameter $A_{H / H}$. These results suggest that the comparison between the two ratio amplitude parameters $\left(A_{H / V}\right.$ and $\left.A_{H / H}\right)$ could provide some information on the presence of remote deep rear fractures, although the presence of an interbedded low-velocity layer could also play a role. Moreover, the $H / V$ curves measured on the Bory site exhibit a plateau-like shape in the low-frequency range, which indicates a 2-D or 3-D site effect probably due to the Bory Crater geometry. This should be investigated in the future. A conclusion of this study is that the first resonance frequency $f_{0}$ of a column is the more reliable parameter for assessing the fracture depth $D$ decoupling a column from the mass, provided that a reasonable estimate of the Young's modulus can be made (seismic prospecting).

\section{ACKNOWLEDGEMENTS}

This work was funded by the ARC project (Région Rhône-Alpes, France), the Interreg project MASSA, the federative organization VOR (Vulnérabilité des Ouvrages aux Risques), the European Project ERC SLIDEQUAKES (grant number ERC-CG2013-PE10-617472), the Agence Nationale de la Recherche ANR LANDQUAKES project (grant number ANR-11-BS01-0016) and C2ROP project. The used seismic instruments belong to the French national collection Sismob-RESIF. Authors express gratitude to the permanent staff of the Observatory of the Piton de la Fournaise (La Reunion Island) for their help during the experiments and the scientific discussions. We thank Romain Biron (LTHE) for providing meteorological data and the National Vercors Park for allowing instrumentation in a protected area. This work would not have been achieved without the help of many people during field work. We are especially grateful to Julien Turpin who died prematurely in 2013.

\section{REFERENCES}

Albarello, D. \& Lunedei, E., 2010. Alternative interpretations of horizontal to vertical spectral ratios of ambient vibrations: new insights from theoretical modeling, Bull. Earthq. Eng., 8(3), 519-534. 
Bonnefoy-Claudet, S., Cotton, F. \& Bard, P.Y., 2006. The nature of noise wavefield and its applications for site effects studies-a literature review, Earth Sci. Rev., 79(3-4), 205-227.

Bottelin, P., 2014. On the pre- and post-rupture phases of mid-size rockfalls: learnings from seismic records., Theses, Université de Grenoble.

Bottelin, P. et al., 2013a. Spectral analysis of prone-to-fall rock compartments using ambient vibrations, Environ. Eng. Geophys. Soc., 18(4), 205217.

Bottelin, P., Levy, C., Baillet, L., Jongmans, D. \& Guéguen, P., 2013b. Modal and thermal analysis of Les Arches unstable rock column (Vercors massif, French Alps), Geophys. J. Int., 194(2), 849-858.

Burjánek, J., Gassner-Stamm, G., Poggi, V., Moore, J. R. \& Fäh, D., 2010. Ambient vibration analysis of an unstable mountain slope, Geophys. $J$. Int., 180(2), 820-828.

Burjánek, J., Moore, J.R., Molina, Y.,F. \& Fäh, D., 2012. Instrumental evidence of normal mode rock slope vibration, Geophys. J. Int., 188(2), 559-569.

Campillo, M., 2006. Phase and correlation in 'random' seismic fields and the reconstruction of the Green function, Pure appl. Geophys., 163(2), 475-502.

Chen, W.-F. \& Lui, E.M., 1997. Handbook of Structural Engineering, CRC Press.

Clinton, J.F., Heaton, T.H. \& Favela, J., 2006. The observed wander of the natural frequencies in a structure, Bull. seism. Soc. Am., 96(1), 237-257.

Danneels, G., Bourdeau, C., Torgoev, I. \& Havenith, H.-B., 2008. Geophysical investigation and dynamic modelling of unstable slopes: case-study of Kainama (Kyrgyzstan), Geophys. J. Int., 175(1), 17-34.

Del Gaudio, V., Coccia, S., Wasowski, J., Gallipoli, M. \& Mucciarelli, M., 2008. Detection of directivity in seismic site response from microtremor spectral analysis, Nat. Hazards Earth Syst. Sci., 8, 751-762.

Del Gaudio, V., Muscillo, S. \& Wasowski, J., 2014. What we can learn about slope response to earthquakes from ambient noise analysis: an overview, Eng. Geol., 182(Part B), 182-200.

Gallipoli, M.R., Lapenna, V., Lorenzo, P., Mucciarelli, M., Perrone, A., Piscitelli, S. \& Sdao, F., 2000. Comparison of geological and geophysical prospecting techniques in the study of a landslide in southern Italy, Eur. J. Environ. Eng. Geophys., 4, 117-128.

Guillier, B., Chatelain, J.-L., Bonnefoy-Claudet, S. \& Haghshenas, E., 2007. Use of ambient noise: from spectral amplitude variability to $\mathrm{H} / \mathrm{V}$ stability, J. Earthq. Eng., 11(6), 925-942.

Haghshenas, E., Bard, P.-Y., Theodulidis, N. \& SESAME, 2008. Empirical evaluation of microtremor H/V spectral ratio, Bull. Earthq. Eng., 6(1), $75-108$.

Jongmans, D. \& Garambois, S., 2007. Geophysical investigation of landslides: a review, Bull. Soc. Géol. France, 178(2), 101-112.

Jongmans, D., Bièvre, G., Renalier, F., Schwartz, S., Beaurez, N. \& Orengo, Y., 2009. Geophysical investigation of a large landslide in glaciolacustrine clays in the Trièves area (French Alps), Eng. Geol., 109(1-2), 45-56.

Le Roux, O., Cornou, C., Jongmans, D. \& Schwartz, S., 2012. 1-D and 2-D resonances in an alpine valley identified from ambient noise measurements and 3-D modelling, Geophys. J. Int., 191(2), 579-590.

Levy, C., 2011. Numerical analysis and geophysical study of the dynamic answer of an unstable rock column, Theses, Université de Grenoble.

Levy, C., Baillet, L., Jongmans, D., Mourot, P. \& Hantz, D., 2010. Dynamic response of the chamousset rock column (western Alps, France), J. geophys. Res., 115(F4), F04043, doi:10.1029/2009JF001606 .
Levy, C., Jongmans, D. \& Baillet, L., 2011. Analysis of seismic signals recorded on a prone-to-fall rock column (Vercors massif, French Alps), Geophys. J. Int., 186(1), 296-310.

Mainsant, G., Larose, E., Brönnimann, C., Jongmans, D., Michoud, C. \& Jaboyedoff, M., 2012. Ambient seismic noise monitoring of a clay landslide: toward failure prediction, J. geophys. Res., 117(F1), F01030, doi:10.1029/2011JF002159.

Mendis, P., Ngo, T., Hristos, N. \& Hira, A., 2007. Wind loading on tall buildings, Electron. J. Struct. Eng., EJSE Special Issue: Loading on Structures, $41-54$.

Méric, O., Garambois, S., MALET, J.-P., Cadet, H., Gueguen, P. \& Jongmans, D., 2007. Seismic noise-based methods for soft-rock landslide characterization, Bull. Soc. Géol. France, 178(2), 137-148.

Michel, C., Guéguen, P. \& Bard, P.-Y., 2008. Dynamic parameters of structures extracted from ambient vibration measurements: an aid for the seismic vulnerability assessment of existing buildings in moderate seismic hazard regions, Soil Dyn. Earthq. Eng., 28(8), 593-604.

Mikael, A., Guéguen, P., Bard, P.-Y., Roux, P. \& Langlais, M., 2013. The analysis of long-term frequency and damping wandering in buildings using the random decrement technique, Bull. seism. Soc. Am., 103(1), 236-246.

Moore, J.R., Gischig, V., Burjánek, J., Loew, S. \& Fäh, D., 2011. Site effects in unstable rock slopes: dynamic behavior of the Randa Instability (Switzerland), Bull. seism. Soc. Am., 101, 3110-3116.

Moser, F., Jacobs, L.J. \& Qu, J., 1999. Modeling elastic wave propagation in waveguides with the finite element method, NDT\&E Int., 32(4), 225-234.

Mucciarelli, M., Gallipoli, M.R., Di Giacomo, D., Di Nota, F. \& Nino, E., 2005. The influence of wind on measurements of seismic noise, Geophys. J. Int., 161(2), 303-308.

Nakamura, Y., 1989. A method for dynamic characteristics estimation of subsurface using microtremor on the ground surface, Q. Rep. Railw. Tech. Res. Inst., 30(1), 25-33.

Özalaybey, S., Zor, E., Ergintav, S. \& Tapirdamaz, M.C., 2011. Investigation of 3-D basin structures in the Izmit bay area (Turkey) by single-station microtremor and gravimetric methods, Geophys. J. Int., 186(2), 883-894.

Peltier, A., Massin, F., Bachèlery, P. \& Finizola, A., 2012. Internal structure and building of basaltic shield volcanoes: the example of the Piton de la Fournaise terminal cone (La Réunion), Bull. Volcanol., 74(8), 1881-1897.

Perrier, L., Metaxian, J.-P., Battaglia, J. \& Garaebiti, E., 2012. Estimation of the near-surface velocity structure of the Yasur-Yenkahe volcanic complex, Vanuatu, J. Volcanol. Geotherm. Res., 227-228, 50-60.

Rix, G.J., Lai, C.G. \& Jr, A.W.S., 2000. In situ measurement of damping ratio using surface waves, J. Geotech. Geoenviron. Eng., 126(5), 472-480.

Semblat, J.F., 1997. Rheological interpretation of rayleigh damping, J. Sound Vib., 206(5), 741-744.

SESAME, 2004. Guidelines for the implementation of the H/V spectral ratio technique on ambient vibrations. Mesasurements, processing and interpretation, Tech. rep., SESAME European Research Project WP12 Deliverable D23-12.

Starr, A.M., Moore, J.R. \& Thorne, M.S., 2015. Ambient resonance of Mesa Arch, Canyonlands National Park, Utah, Geophys. Res. Lett., 42(16), 6696-6702.

Toksoz, M.N., Johnston, D.H. \& Timur, A., 1979. Attenuation of seismic waves in dry and saturated rocks: I. Laboratory measurements, Geophysics, 44(4), 681-690. 


\section{MODELLING OF WIND SPEED EFFECT}

(a)

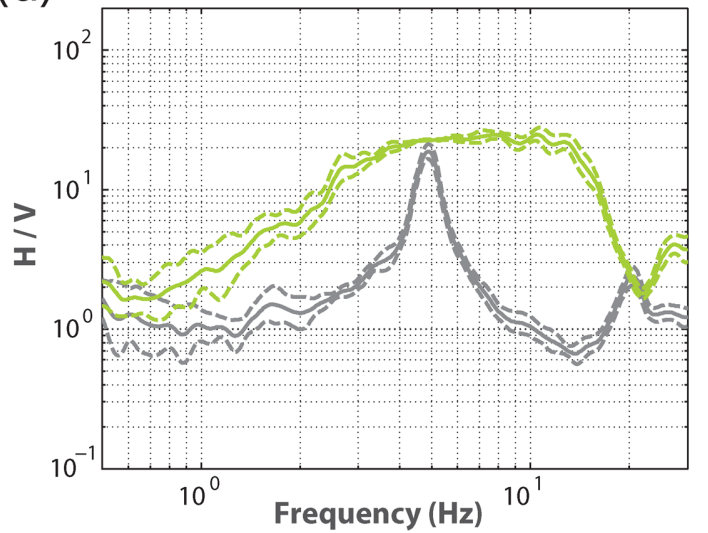

(b)

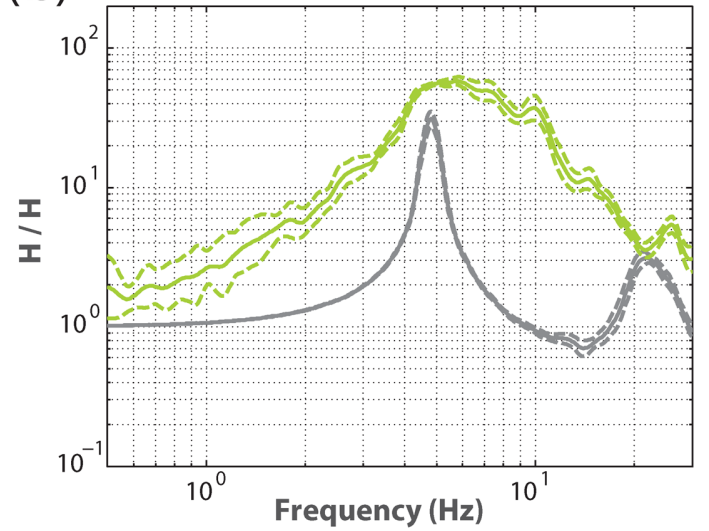

Figure A1. Comparison between numerical modelling results ( $T_{1}=4 \mathrm{~m} ; D_{1}=15 \mathrm{~m} ; E=10 \mathrm{GPa}$ ) for no-wind (in grey) and strong wind conditions (in green). (a) $H / V$ curves. (b) $H / H$ curves. Plain lines are mean curves and dashed lines represent \pm one standard deviation around the mean. The horizontal wind pressure on the cliff was applied for wind speed Sw between 3 and $5 \mathrm{~m} \mathrm{~s}^{-1}$ (see Fig. 3c).

\section{APPENDIX B: EFFECT OF DAMPING (5 PER CENT)}

(a)

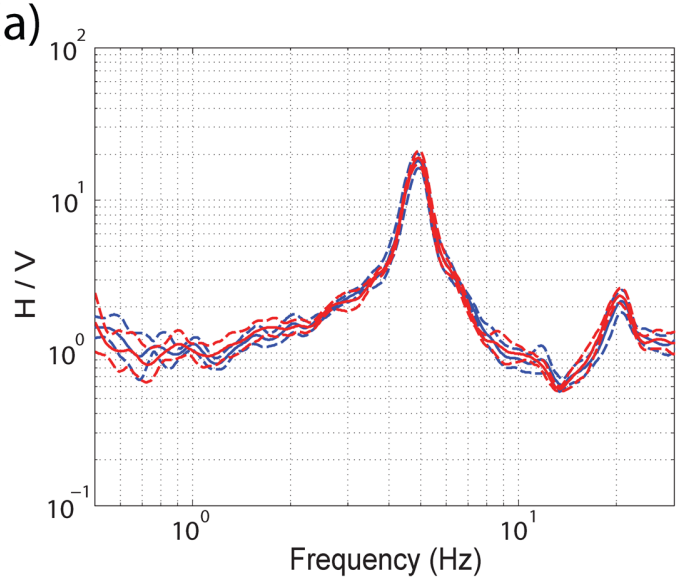

(b)

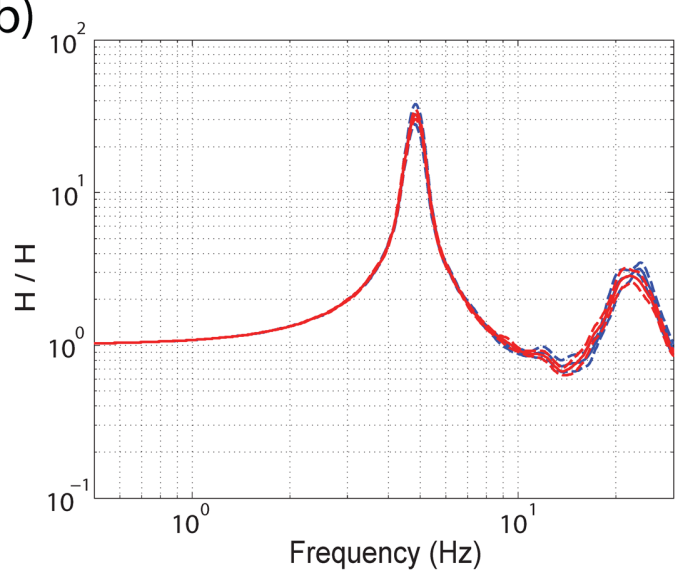

Figure B1. Comparison of the $H_{1} / V_{1}$ and $H_{1} / H_{2}$ spectral ratios computed with and without attenuation (red and blue curves, respectively). Plain lines are mean curves and dashed lines represent \pm one standard deviation around the mean. 


\section{APPENDIX C:PARAMETRIC STUDY}

Table C1. Values of the dynamic parameters $\left(f_{0}, A_{H / V}\right.$ and $\left.A_{H / H}\right)$ computed from the 54 numerical models with variations of the column characteristics $T_{1}$ (thickness), $D_{1}$ (fracture depth) and $E$ (Young's modulus).

\begin{tabular}{|c|c|c|c|c|c|}
\hline$E(\mathrm{GPa})$ & $T_{1}(\mathrm{~m})$ & $D_{1}(\mathrm{~m})$ & $f_{0}(\mathrm{~Hz})$ & $A_{H / V}$ & $A_{H / V}$ \\
\hline 2 & 2 & 5 & 8.898 & 8.585 & 24.047 \\
\hline 2 & 2 & 7.5 & 4.967 & 17.660 & 28.733 \\
\hline 2 & 2 & 10 & 2.999 & 19.180 & 38.299 \\
\hline 2 & 2 & 15 & 1.467 & 31.656 & 50.890 \\
\hline 2 & 2 & 20 & 0.867 & 44.640 & 78.704 \\
\hline 2 & 2 & 25 & 0.567 & 41.930 & 68.288 \\
\hline 2 & 4 & 5 & 10.202 & 5.432 & 16.764 \\
\hline 2 & 4 & 7.5 & 6.066 & 10.527 & 20.676 \\
\hline 2 & 4 & 10 & 4.133 & 13.391 & 24.620 \\
\hline 2 & 4 & 15 & 2.200 & 17.742 & 29.746 \\
\hline 2 & 4 & 20 & 1.334 & 29.347 & 38.156 \\
\hline 2 & 4 & 25 & 0.900 & 35.860 & 49.797 \\
\hline 2 & 6 & 5 & 10.099 & 4.056 & 12.655 \\
\hline 2 & 6 & 7.5 & 7.068 & 6.360 & 17.525 \\
\hline 2 & 6 & 10 & 4.665 & 10.722 & 19.257 \\
\hline 2 & 6 & 15 & 2.700 & 17.877 & 24.379 \\
\hline 2 & 6 & 20 & 1.700 & 22.843 & 28.309 \\
\hline 2 & 6 & 25 & 1.199 & 24.661 & 36.761 \\
\hline 10 & 2 & 5 & 19.180 & 8.316 & 28.079 \\
\hline 10 & 2 & 7.5 & 10.922 & 16.110 & 32.337 \\
\hline 10 & 2 & 10 & 6.694 & 22.845 & 38.837 \\
\hline 10 & 2 & 15 & 3.275 & 31.129 & 54.369 \\
\hline 10 & 2 & 20 & 1.937 & 35.991 & 51.604 \\
\hline 10 & 2 & 25 & 1.243 & 44.130 & 69.517 \\
\hline 10 & 4 & 5 & 21.459 & 5.251 & 15.999 \\
\hline 10 & 4 & 7.5 & 13.194 & 8.507 & 19.104 \\
\hline 10 & 4 & 10 & 9.072 & 13.204 & 24.118 \\
\hline 10 & 4 & 15 & 4.959 & 19.128 & 32.421 \\
\hline 10 & 4 & 20 & 3.027 & 30.144 & 36.696 \\
\hline 10 & 4 & 25 & 2.036 & 32.616 & 47.463 \\
\hline 10 & 6 & 5 & 21.410 & 4.245 & 11.434 \\
\hline 10 & 6 & 7.5 & 15.117 & 7.045 & 16.945 \\
\hline 10 & 6 & 10 & 10.410 & 9.009 & 19.242 \\
\hline 10 & 6 & 15 & 6.000 & 15.027 & 22.698 \\
\hline 10 & 6 & 20 & 3.836 & 17.665 & 32.373 \\
\hline 10 & 6 & 25 & 2.640 & 24.817 & 34.748 \\
\hline 20 & 2 & 5 & 25.843 & 8.204 & 25.359 \\
\hline 20 & 2 & 7.5 & 15.133 & 14.374 & 31.231 \\
\hline 20 & 2 & 10 & 9.365 & 22.026 & 38.437 \\
\hline 20 & 2 & 15 & 4.601 & 31.437 & 49.115 \\
\hline 20 & 2 & 20 & 2.733 & 35.508 & 52.681 \\
\hline 20 & 2 & 25 & 1.767 & 47.812 & 84.508 \\
\hline 20 & 4 & 5 & 28.837 & 5.613 & 13.304 \\
\hline 20 & 4 & 7.5 & 18.227 & 9.015 & 18.565 \\
\hline 20 & 4 & 10 & 12.768 & 14.116 & 22.614 \\
\hline 20 & 4 & 15 & 6.932 & 18.401 & 32.293 \\
\hline 20 & 4 & 20 & 4.233 & 24.648 & 37.089 \\
\hline 20 & 4 & 25 & 2.866 & 32.210 & 43.506 \\
\hline 20 & 6 & 5 & 28.757 & 4.087 & 12.489 \\
\hline 20 & 6 & 7.5 & 20.736 & 6.288 & 14.299 \\
\hline 20 & 6 & 10 & 14.398 & 11.164 & 20.920 \\
\hline 20 & 6 & 15 & 8.466 & 17.652 & 24.608 \\
\hline 20 & 6 & 20 & 5.401 & 19.755 & 28.883 \\
\hline 20 & 6 & 25 & 3.735 & 26.653 & 38.576 \\
\hline
\end{tabular}




\section{APPENDIX D: EFFECT OF THE DEPTH} OF A SECOND FRACTURE $\left(D_{2}\right)$
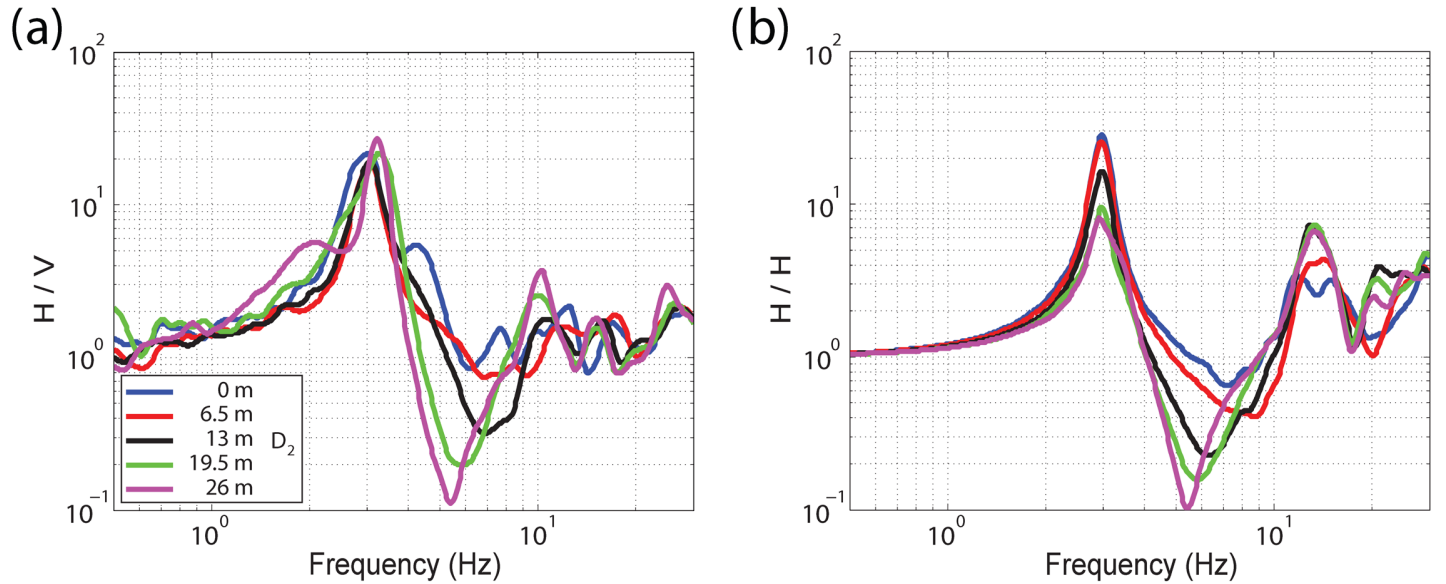

Figure D1. Influence of the depth value of a second fracture $\left(D_{2}\right)$ on the $H / V$ and $H / H$ spectral ratios. The peak of the $H / H$ ratio $\left(A_{H / H}\right)$ decreases when $D_{2}$ reaches the same value as the first fracture depth $(13 \mathrm{~m})$

\section{APPENDIX E: 3-D MODAL ANALYSIS \\ OF THE BORY COLUMN}
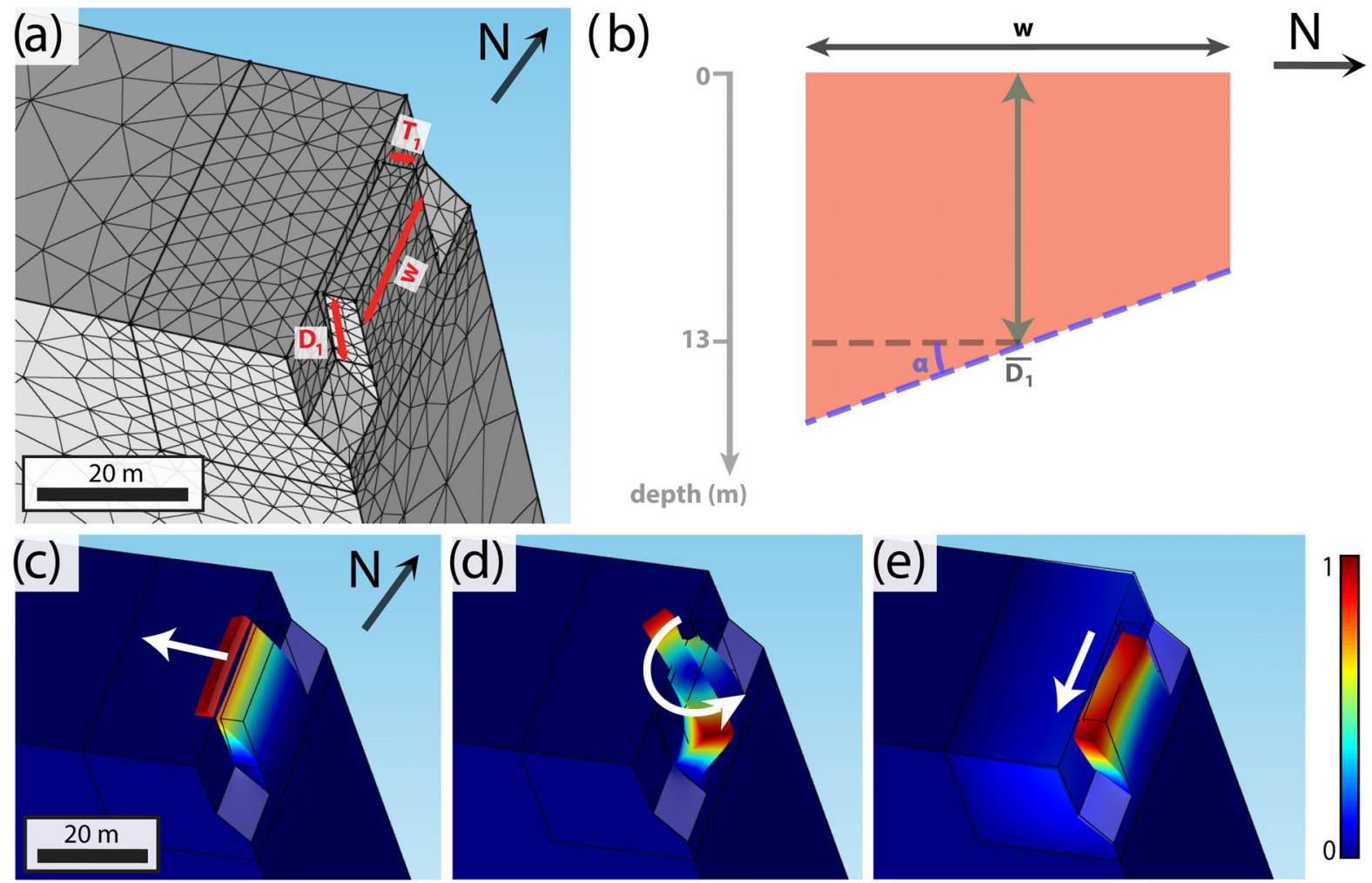

Figure E1. 3-D numerical FE modelling of the dynamic response of the Bory column. (a) Tetrahedral mesh of the model with the column refined zone (25 $\times 25 \times 40 \mathrm{~m})$ of depth $D_{1}$, thickness $T_{1}(4 \mathrm{~m})$ and width $w(20 \mathrm{~m})$. (b) Geometry of the rear fracture. The fracture bottom (dashed purple line) is located at the average depth $D_{1}$ and is tilted by an angle $\alpha$. (c-e) 3-D modal analysis of the Bory column $\left(D_{1}=13 \mathrm{~m}\right.$ and $\left.\alpha=0^{\circ}\right)$ for the three first resonance modes. The motion scale is normalized by the maximal displacement for each mode: (c) first bending mode (perpendicular to the rear fracture) at $2.78 \mathrm{~Hz}$, (d) second torsion mode at $4.77 \mathrm{~Hz}$ and (e) third bending mode (parallel to the rear fracture) at $5.73 \mathrm{~Hz}$. The effect of the rear fracture dip $\alpha$ on the three first resonance modes is shown in Table E1. 
Table E1. Characteristics of the rear fracture geometry $\left(D_{1}\right.$ and $\alpha$ : average depth and dip of the fracture bottom, respectively) and frequencies of the three first resonance modes $\left(f_{0}\right.$ : first bending mode; $f_{1}$ : second torsion mode; $f_{2}$ : third bending mode) for a column with a thickness $T_{1}=4 \mathrm{~m}$, a width $w=20 \mathrm{~m}$ and a Young's modulus $E=2 \mathrm{GPa}$.

\begin{tabular}{lcccc}
\hline$D_{1}(\mathrm{~m})$ & $\alpha($ degree $)$ & $f_{0}(\mathrm{~Hz})$ & $f_{1}(\mathrm{~Hz})$ & $f_{2}(\mathrm{~Hz})$ \\
\hline 13 & 0 & 2.78 & 4.77 & 5.73 \\
13 & 5 & 2.78 & 4.80 & 5.74 \\
13 & 10 & 2.79 & 4.87 & 5.77 \\
13 & 15 & 2.81 & 4.98 & 5.82 \\
13 & 20 & 2.83 & 5.13 & 5.88 \\
13 & 25 & 2.87 & 5.37 & 5.96 \\
13 & 30 & 2.91 & 5.62 & 6.08 \\
12 & 0 & 3.14 & 5.17 & 5.96 \\
14 & 0 & 2.64 & 4.42 & 5.46 \\
\hline
\end{tabular}

\section{APPENDIX F: EFFECT OF THE SCORIA}

\section{LAYER}
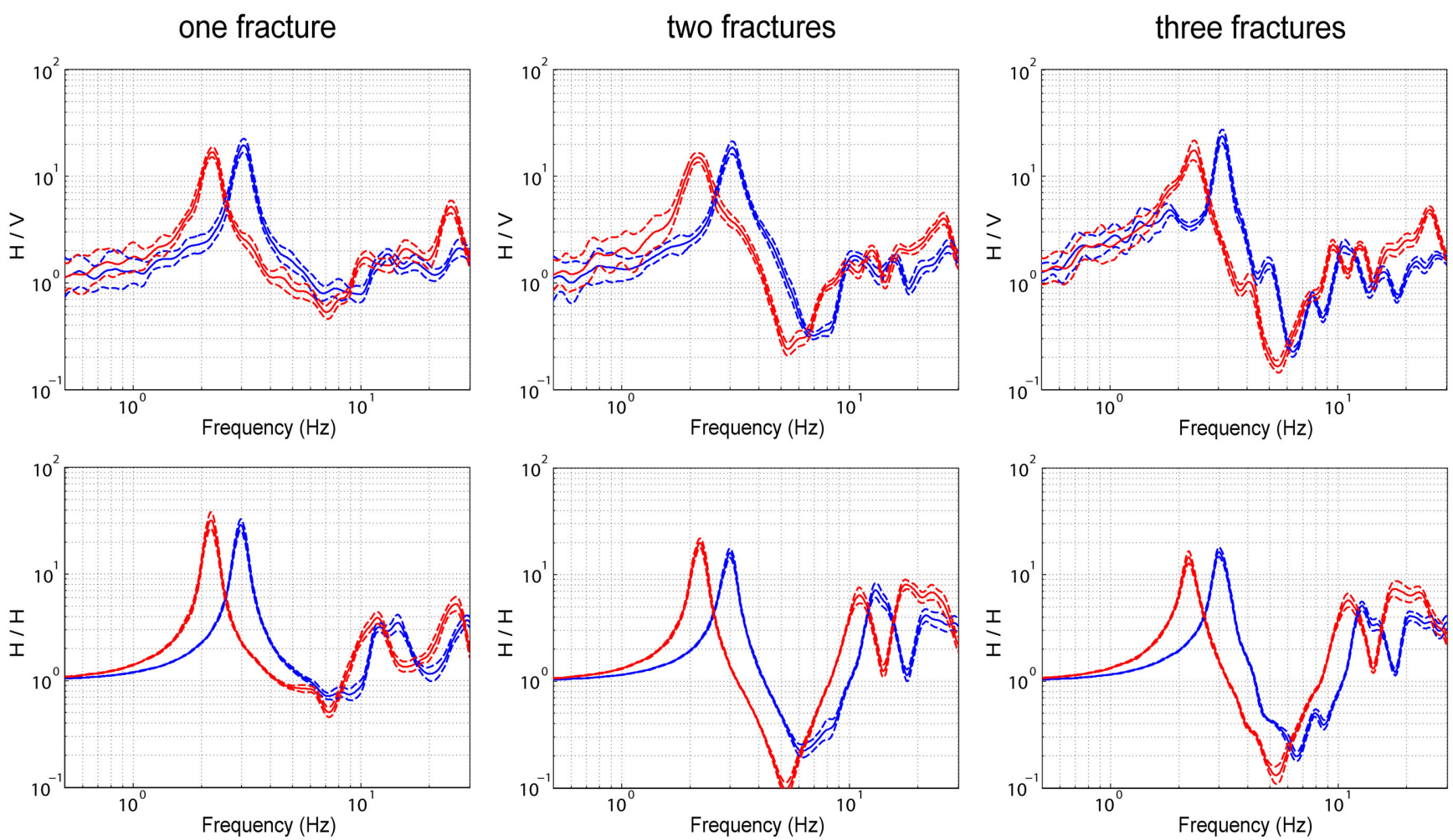

Figure F1. Bory site. Effect of the scoria layer on the $H / V$ (top row) and $H / H$ curves (bottom row) for 1, 2 and 3 fractures. The curves with and without the scoria layer are in red and blue, respectively. The dynamic characteristics in the scoria are $V p=800 \mathrm{~m} \mathrm{~s}^{-1} ; V s=400 \mathrm{~m} \mathrm{~s}^{-1}$, density $=2000 \mathrm{~kg} \mathrm{~m}{ }^{-3}$ and $E=$ $0.85 \mathrm{GPa}$. Plain lines are mean curves and dashed lines represent \pm one standard deviation around the mean. 